\title{
APARATOS DE ESTABILIZACION Y DE REEMPLAZO DE USO CORRIENTE EN ARTRODESIS Y ARTROPLASTIAS DE LA COLUMNA CERVICAL
}

\section{Dr. César García M(1).}

1. Radiólogo Departamento de Imágenes Clínica, Alemana de Santiago-Chile.

\section{STABILIZATION AND REPLACEMENT DEVICES CURRENTLY USED IN ARTHRODESIS AND ARTHROPLASTIES OF THE CERVICAL SPINE}

\begin{abstract}
Continuous advances in diagnosis and treatment of cervical spine diseases have modified their surgical indications. Complex degenerative cervical disease not responding to conservative treatment is its main indication, with an important increase in these types of surgical procedures, also including trauma, scoliosis/deformities and neoplasm. Having knowledge of devices currently used in arthroplasty and arthrodesis, their general indications, biomechanics and complications enables radiologists to get accurate image interpretation as well as to render adequate radiology reports.

Keywords: Biomechanics Spine fusion, Cervical, Cervical surgery, Spinal instrumentation, Spine arthroplasty, Trends.
\end{abstract}

Resumen: Los avances diagnósticos y terapéuticos de las enfermedades de la columna vertebral modificaron sus indicaciones quirúrgicas. La enfermedad degenerativa complicada sin respuesta al tratamiento conservador, es su principal indicación y va en aumento; también incluye traumatismos, escoliosis/ deformidades y neoplasias. Conocer los tipos generales de elementos utilizados en artroplastías y artrodesis, las indicaciones generales, biomecánica y complicaciones, permite a los radiólogos una mejor evaluación de estas imágenes y la elaboración de un informe radiológico adecuado.

Palabras clave: Artroplastía vertebral, Biomecánica Cirugía cervical, Tendencias. Fusión vertebral; Cervical, Instrumentación espinal.

García C. Aparatos de estabilización y de reemplazo de uso corriente en artrodesis y artroplastías de la columna cervical. Rev Chil Radiol 2008; 14: 181-199.

Correspondencia: Dr. César García M.

cgarcia@alemana.cl.

Trabajo recibido el 25 de julio de 2008, aceptado para publicación el 11 de noviembre de 2008.

\section{Introducción}

Los avances en el diagnóstico y tratamiento de las enfermedades de la columna vertebral son cada vez más vertiginosos y están relacionados con una mejor comprensión de la biomecánica de la columna (especialmente la evaluación tridimensional), con técnicas quirúrgicas menos invasivas, con los materiales usados en los elementos de estabilización, en los injertos y biomateriales utilizados para la fusión, el desarrollo de prótesis discales, los avances en tomografía computada (TC) (reconstrucciones 3D) y resonancia magnética (RM) (evaluación de médula y raíces) $)^{(1,2)}$.

Si bien un porcentaje menor de la patología degenerativa, tumoral y de deformidades de la columna requiere cirugía, ésta es el tratamiento de elección para la mayoría de los pacientes con lesiones traumáticas.

Los radiólogos deben interpretar adecuadamente las imágenes post quirúrgicas y sugerir las modalidades más adecuadas para el caso particular, acorde al contexto clínico, traduciéndolo en un informe radiológico útil, en el marco de los protocolos utilizados en sus instituciones ${ }^{(3)}$.

Nuestro objetivo es mostrar los grupos de elementos de estabilización y de reemplazo, sus indicaciones, complicaciones y principios biomecánicos básicos, para que con estos conocimientos se pueda elaborar un informe radiológico útil, consensuado con los clínicos.

\section{Artrodesis y artroplastías}

Estabilidad es la capacidad de la columna para resistir la deformación producida por las fuerzas fisiológicas que actúan sobre ella, evitando desplazamientos, deformaciones y compromiso neurológico. Se habla de inestabilidad aguda cuando hay daño de ligamentos o fractura de cuerpos vertebrales o facetas. La inestabilidad crónica se asocia a enfermedad discal, artropatía facetaria degenerativa o daño traumático ligamentoso, que es ineficiente para el control de la movilidad de la unidad funcional vertebral. Puede ser uni o multisegmentaria.

Existen distintas técnicas y abordajes quirúrgicos 
para realizar una artrodesis y corregir la inestabilidad. La artrodesis tiene como objetivo la fusión espinal, para lo que se utiliza instrumentación con diversos elementos de fijación o estabilización. Los aparatos de fijación proporcionan estabilidad inmediata, por un período limitado de tiempo, mejorando y facilitando los porcentajes de fusión espinal, pero no pueden resistir el estrés fisiológico prolongado por lo que en la mayoría de los casos fallan si no se produce una fusión sólida. Producida ésta, los fijadores no son necesarios pero se dejan in situ indefinidamente por los riesgos asociados con las cirugías repetidas. Sólo se remueven por infección o dolor resistente a tratamiento. El objetivo final es obtener una artrodesis estable que evite la pseudo $\operatorname{artrosis}^{(4,5)}$

La artroplastía con prótesis discales se usa en el tratamiento de la enfermedad degenerativa complicada y dolorosa. Tiene como objetivo preservar la movilidad del segmento intervenido, evitando las complicaciones de la fijación.

\section{Artrodesis: Elementos de fijación de uso corriente}

Se usan placas, placas-caja, cajas, tornillos, alambres y ganchos laminares y pediculares, aislados o en combinación, diseñados y fabricados especialmente para adaptarse a la columna cervical. En general, según su acción biomecánica, se clasifican en cinco grupos funcionales: distracción y compresión, estabilización segmentaria, sistemas de acoplamiento o desrotación, sistemas translacionales o tornillos pediculares e instrumentación anterior ${ }^{(6)}$.

El "halo-vest" es un collar sólido completo o no, anclado al cráneo con tornillos y sostenido por una abrazadera rígida que rodea los hombros, con conexiones ajustables que facilitan el control tridimensional de la relación hombros-cráneo, que puede ser utilizado aislado o en combinación con elementos de fijación. Produce estabilización externa y puede comprimir, neutralizar o distraer. En general, las distracciones en columna traumática no son adecuadas $^{(7)}$ (Figura 1).

\section{Topografía de la artrodesis de la columna cervical}

La morfología y la biomecánica de la unión occípito-cervical del segmento C1-C2 y del segmento subaxial difieren, por lo que las analizaremos separadamente.

\section{Unión cráneo-cervical}

La fusión occípito-cervical utiliza distintos elementos de fijación. Está indicada en trauma, enfermedades congénitas, reumatológicas y neoplásicas. Las placas occípito-cervicales son de diseño especial, premoldeadas; en caso contrario, se deben moldear en el pre operatorio, ajustándose a la radiografía pre-quirúrgica para asegurar la buena posición del cráneo, donde se fijan con tornillos o alambres ${ }^{(8)}$.

Las malformaciones óseas cráneo-vertebrales congénitas son complejas, con sintomatología derivada de compresión neural, mal alineamiento óseo, distintos grados de inestabilidad. Utilizan fijaciones con barras o alambres $^{(9)}$ (Figuras 2, 3).

En trauma, las principales indicaciones son: disociación traumática atlanto-occipital y fractura de cóndilos occipitales tipo III de Anderson-Montesano (avulsión de cóndilos occipitales). También en ciertas fracturas atlas-axis se utilizan fijaciones con placas occípito-cervicales $^{(9,10)}$ (Figura 4).
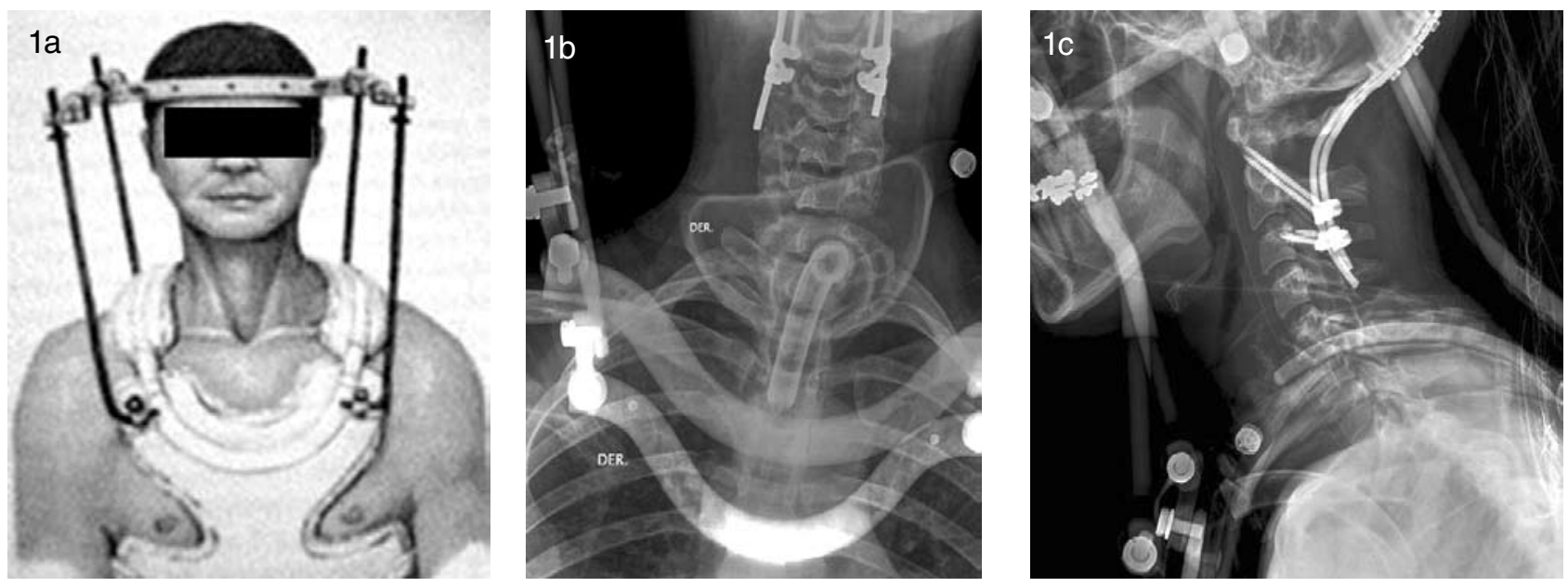

Figura 1. Halo-vest. Esquema (a) y radiografías $A P-L(b, c)$ de artrodesis cráneo-cervical por fractura de C2, muestran los componentes del chaleco que consta de 4 barras metálicas que unen el anillo cervical al componente torácico. 
En artritis reumatoide con inestabilidad cervical, incluso se han utilizado fusiones occípito-torácicas para estabilizaciones multisegmentarias largas ${ }^{(11)}$.

\section{Segmento atlas-axis}

La principal indicación es el trauma. Las vías de abordaje, técnicas quirúrgicas, y elementos de fijación utilizados son variadas pero el estándar de oro parece ser la fijación con tornillos trans-pediculares. Analizaremos las más utilizadas.

Las técnicas de alambrado posterior dan buena estabilidad a la flexión y extensión pero son poco adecuadas en las rotaciones, lo que aumenta el grado de uniones fallidas. Estas técnicas han ido mejorando, con mayor grado de estabilización rotatoria y en combinación con el uso del halo; el éxito de la fusión alcanza cerca del $97 \%{ }^{(12)}$ (Figura 5).

Sin embargo, existe consenso que las amarras C1 C2 asociadas a tornillos transpediculares dan la mayor estabilidad y no tienen las enormes com- plicaciones del halo.

La fijación interlaminar con ganchos laminares se utiliza si las láminas de C1 y C2 están intactas, sin cambios degenerativos importantes u osteoporosis acentuada. Los ganchos se ponen en la superficie superior de la lámina de C1 y la inferior de C2, completando con injertos óseos intercalares; estabilizan bien las fuerzas de flexión y extensión. Sin embargo, no son tan efectivas con las fuerzas rotacionales como otros métodos de fijación posterior ${ }^{(13)}$.

Los tornillos transpediculares, utilizados en algunos tipos de fracturas de odontoides y espondilolistesis traumática de $\mathrm{C} 2$, tienen la ventaja que suprimen los movimientos rotatorios de la articulación atlas-axis. Sus desventajas son la eventualidad de complicaciones neurológicas o vasculares serias que se reducen con el uso de CT y RM en la planificación pre-operatoria. Para la mayoría de los autores, este es el estándar de oro para reestabilizar este segmento $^{(14,15)}$ (Figuras 1, 4).
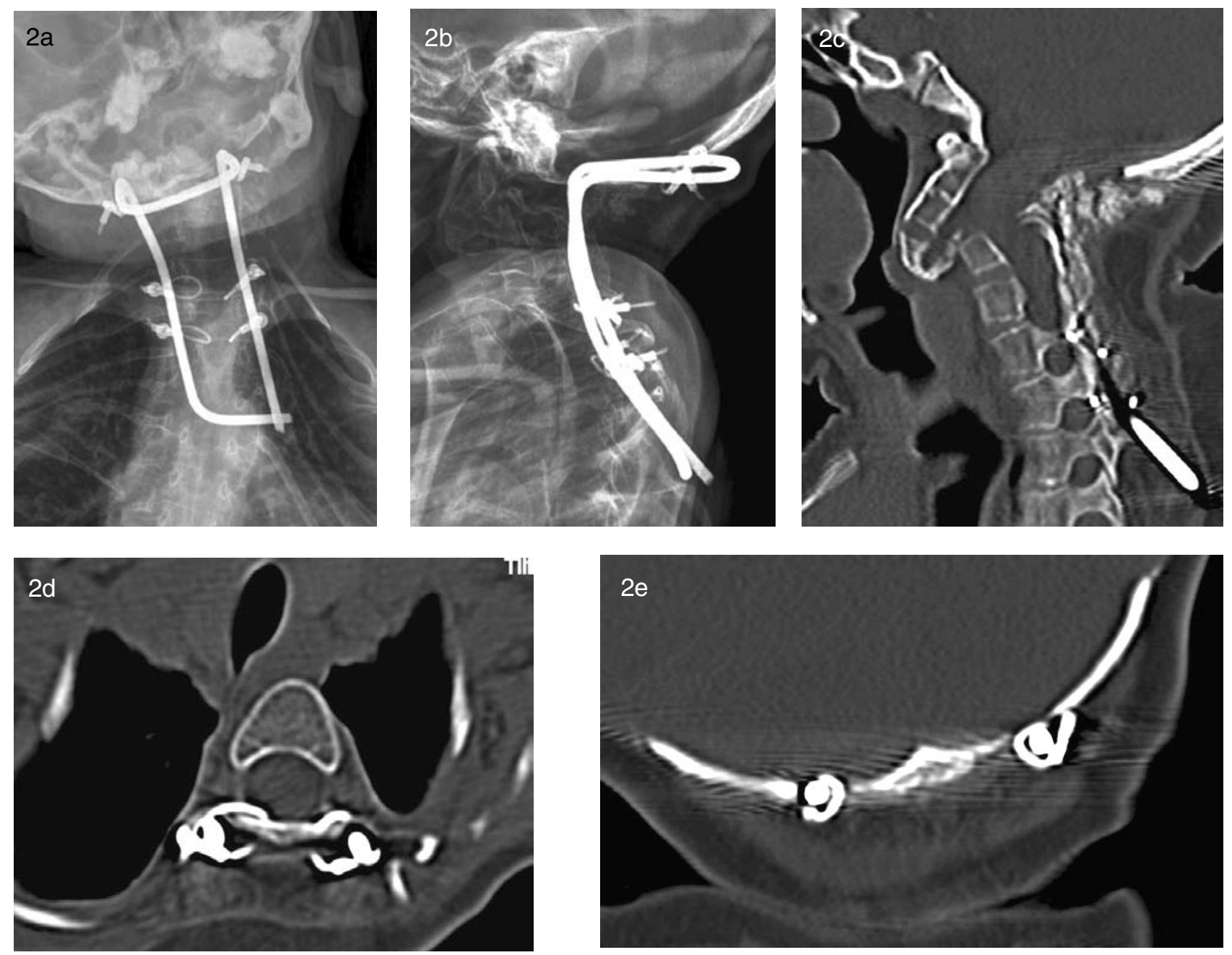

Figura 2. Barras cráneo-cervicales. Radiografías AP-L (a,b), paciente de 15 años con síndrome malformativo complejo. Fusión occípito-dorsal para corregir mielopatía compresiva, con barras moldeadas unidas con cables tipo Songer al occipital y a los pedículos T3 y T4. Reconstrucción sagital y cortes axiales de TC del mismo niño (c) muestra parte de la malformación estabilizada y el curso de los alambres por los pedículos dorsales (d) y las tablas del parietal (e). 

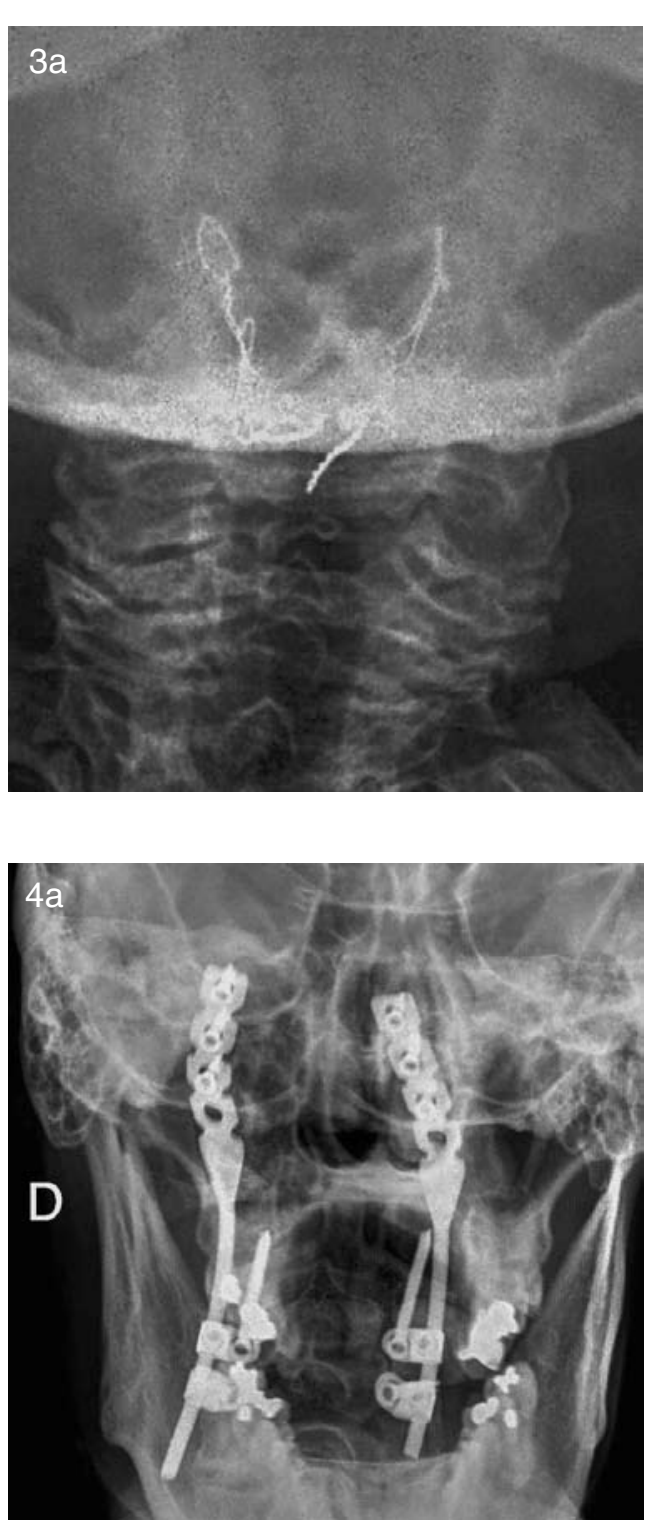

Figura 4. Fijación occípito-cervical en paciente de 77 años; radiografías $A P-L(a, b)$ Inestabilidad atlantoaxoidea, corregida quirúrgicamente con fusión cráneocervical. CervifixR fijado al occipital y a C2 y C3, con tornillos transpediculares.
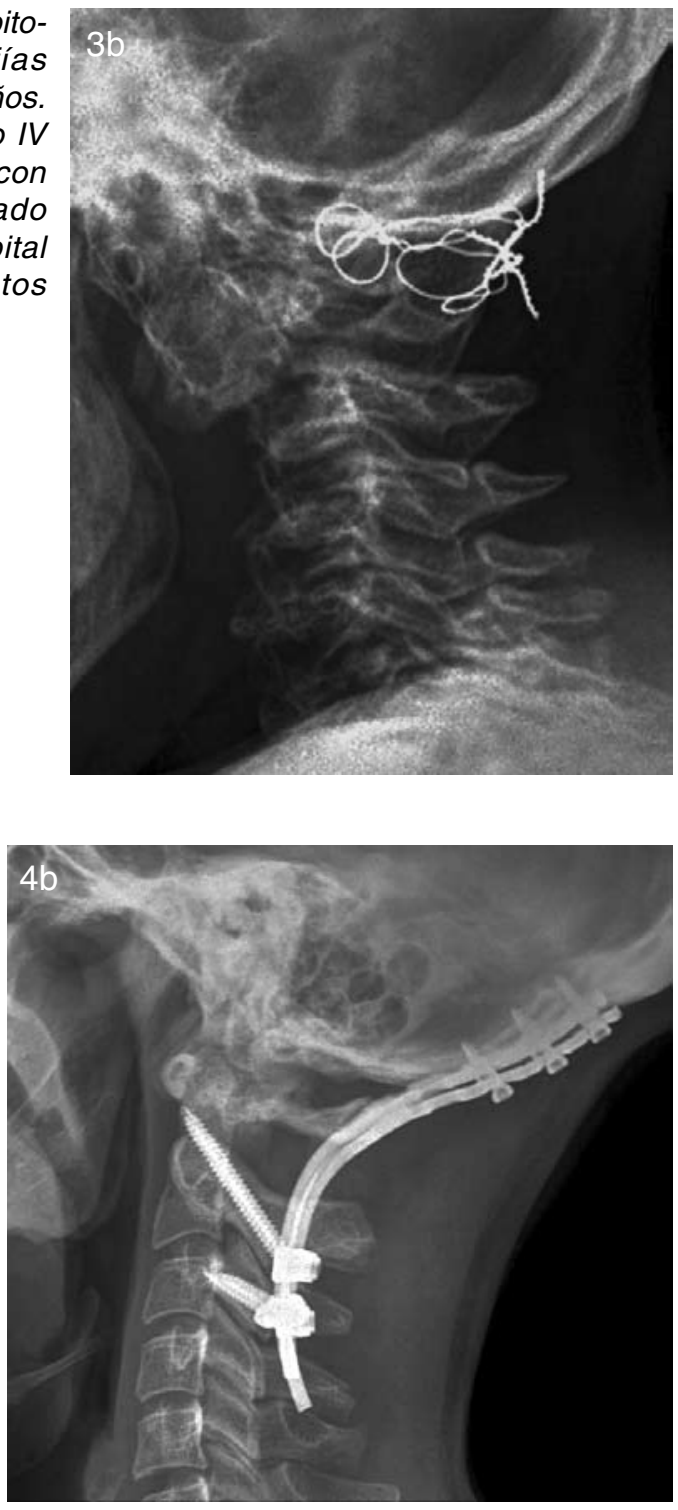
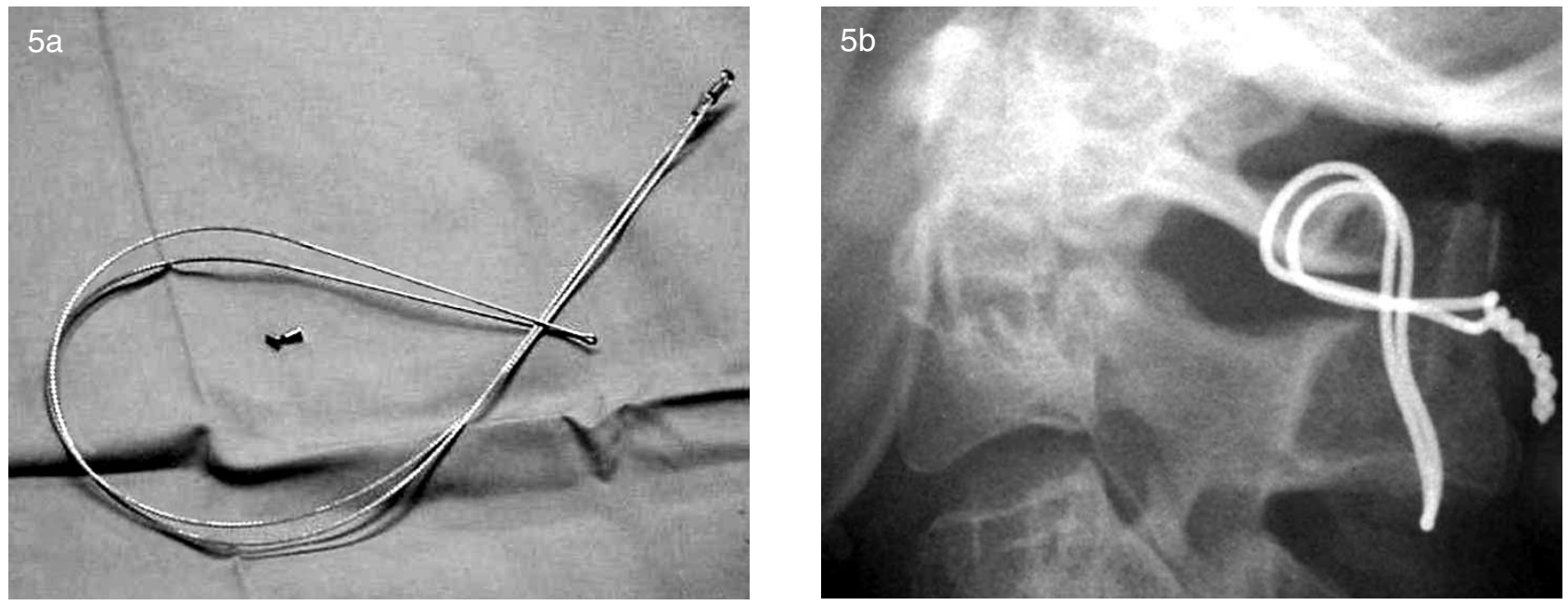

Figura 5. Alambrado posterior. Fotografía de cable de Songer (a) que se utiliza en fijaciones posteriores de columna, con un sistema para bloqueo. Radiografía lateral localizada (b) mostrando una fractura de la base del odontoides fijada con alambre interespinoso C1-C2, más injerto óseo. 
La fijación anterior con tornillos de las fracturas de odontoides tipo II produce estabilización inmediata, conserva la rotación de C1 sobre C2 y permite una recuperación rápida. Su creciente aceptación se debe a mejores sistemas de instrumentación, técnica quirúrgica mínimamente invasiva e imágenes seccionales de alta resolución. Se utiliza un tornillo canulado con hilado parcial, colocado a través de la cortical inferior de C2 hacia la odontoides. Actúa como tornillo ínterfragmentario. Al ser canulado, permite una inserción y ubicación más precisa al avanzar sobre guías de alambre $^{(16)}$ (Figura 6).

\section{Segmento subaxial de la columna cervical A) Fijaciones anteriores}

Emplean placas, placas-caja, cajas y tornillos, aislados o en combinación. Se utilizan principalmente en enfermedad degenerativa, también en trauma, tumor o infección. Como adyuvantes, en casi todos los casos se utilizan injertos óseos.

\section{Placas cervicales anteriores}

Se utilizan para recuperar la estabilidad clínica de una columna con inestabilidad estructural, mantener el alineamiento tras corregir una deformidad o prevenir su progresión y aliviar el dolor (Figuras 7 y 8).

Mejoran la tasa de fusión de los injertos y disminuyen el número de pseudo-artrosis o de cifosis post-discectomías y fusiones multi-segmentarias, principalmente al usar placas dinámicas, cuyo desarrollo fue impulsado por la mayor comprensión de la biomecánica del conjunto implante-columna, y en especial por el rol del "efecto escudo" o "armadura protectora" (stress shielding) y de la subsidencia del injerto(17) (Figura 9).

El efecto escudo es la disminución de la consolidación ósea inducida por el implante cuando recibe estrés y carga excesivas. Se sabe que hasta el $70 \%$ de la carga debería trasmitirse a través de la columna, no del implante, para el funcionamiento óptimo, tanto de la artrodesis como de la estabilidad inicial. Es decir, en una fusión con efecto escudo del implante, las fuerzas compresivas no se transmitirán adecuadamente a las superficies de fusión injertovértebra, produciendo retardo en la consolidación o pseudo artrosis.

Subsidencia es la pérdida de altura en el sitio quirúrgico durante su evolución post-operatoria debido a reabsorción/remodelación; es un proceso complejo que ocurre normalmente durante la cicatrización. No es un proceso patológico y, por lo general termina en la fusión. En cambio el colapso del injerto, si es patológico, se produce antes de su asimilación y lleva a una subsidencia excesiva, con falla del injerto (Figura 10).

En ciertos casos, al fracturarse un implante (placa/tornillo), las fuerzas de cicatrización ósea se
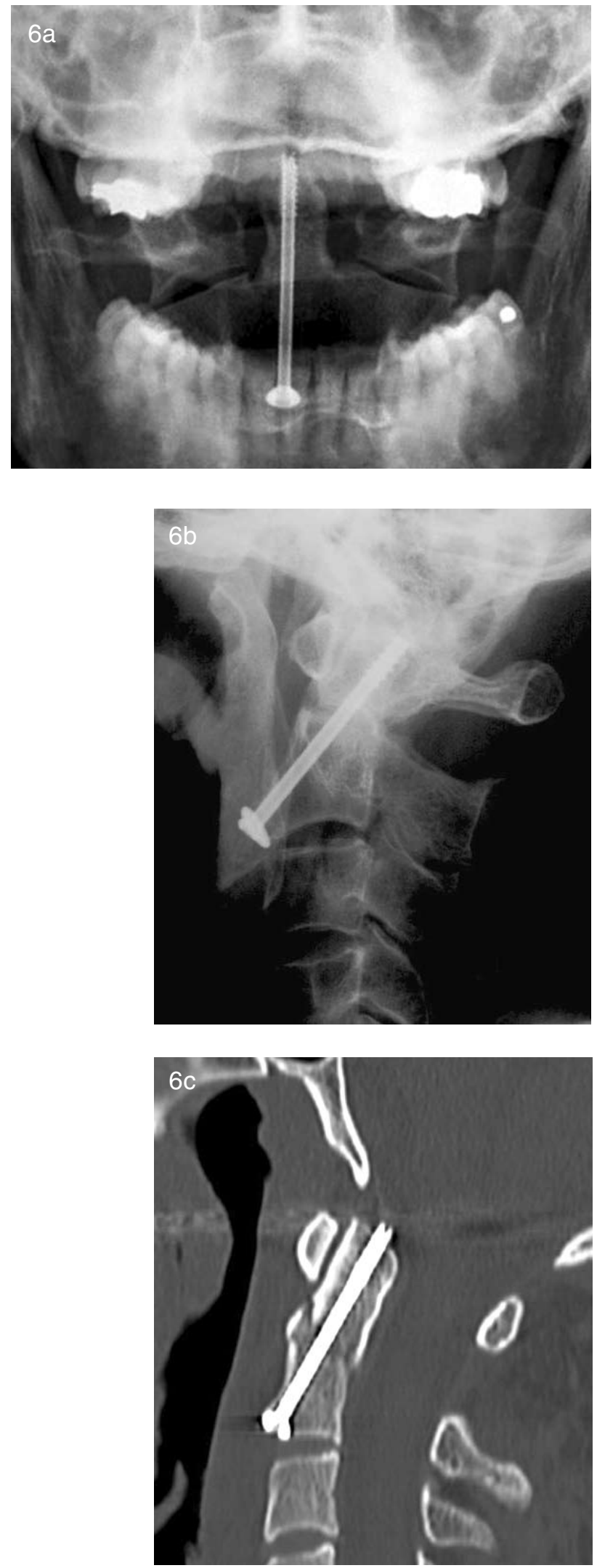

Figura 6. Tornillo canulado anterior; paciente de 35 años. Radiografías AP-L (a,b) y TC (c) muestran fractura de odontoides tipo II, estabilizada con tornillo canulado del cuerpo de C2 a la apófisis odontoides; actúa como tornillo interfragmentario de esponjosa con hilado parcial. 
ejercen efectivamente sobre el injerto, favoreciendo la fusión que de otro modo, si la placa no falla, habría terminado en pseudoartrosis. Esto se conoce como "dinamismo positivo"(18) (Figura 11).

Las placas anteriores, especialmente las rígidas, se pueden complicar en el punto de mayor estrés de los distintos componentes del implante, con mayor frecuencia en la unión tornillo-placa, con tasas que varían en diversos estudios. Las placas bloqueadas tienen tornillos bloqueados, cuyo diseño minimiza el riesgo de desplazamiento de los componentes. Las placas dinámicas, en cambio, no pueden bloquear los tornillos, pues es justamente la posibilidad de deslizamiento de los tornillos lo que permite el movimiento de la placa y la compresión subsiguiente, disminuyendo la posibilidad de falla del implante ${ }^{(19)}$.

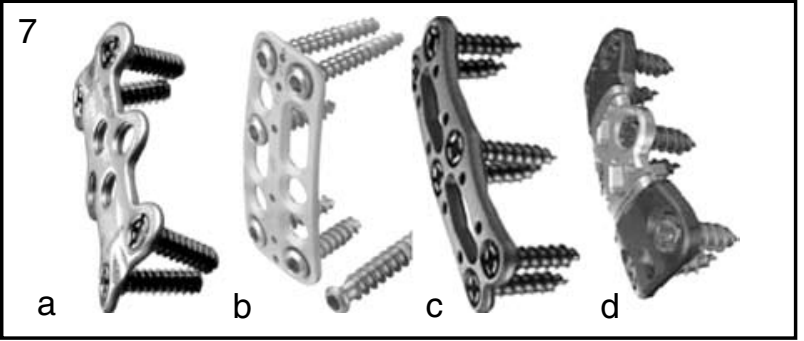

Figura 7. Algunas placas utilizadas en fijación cervical anterior.(a) Placa rígida que usa sólo tornillos de ángulo fijo (SynthesR), (b) Placa semi-rígida CasparR (ABC Cister, Braun, España), permite cierto grado de desplazamiento del tornillo, (c,d) Placas para fijación anterior dinámica (VectraR y Vectra-TR Synthes), permiten subsidencia por sus agujeros amplios que facilitan la translación axial y angular.
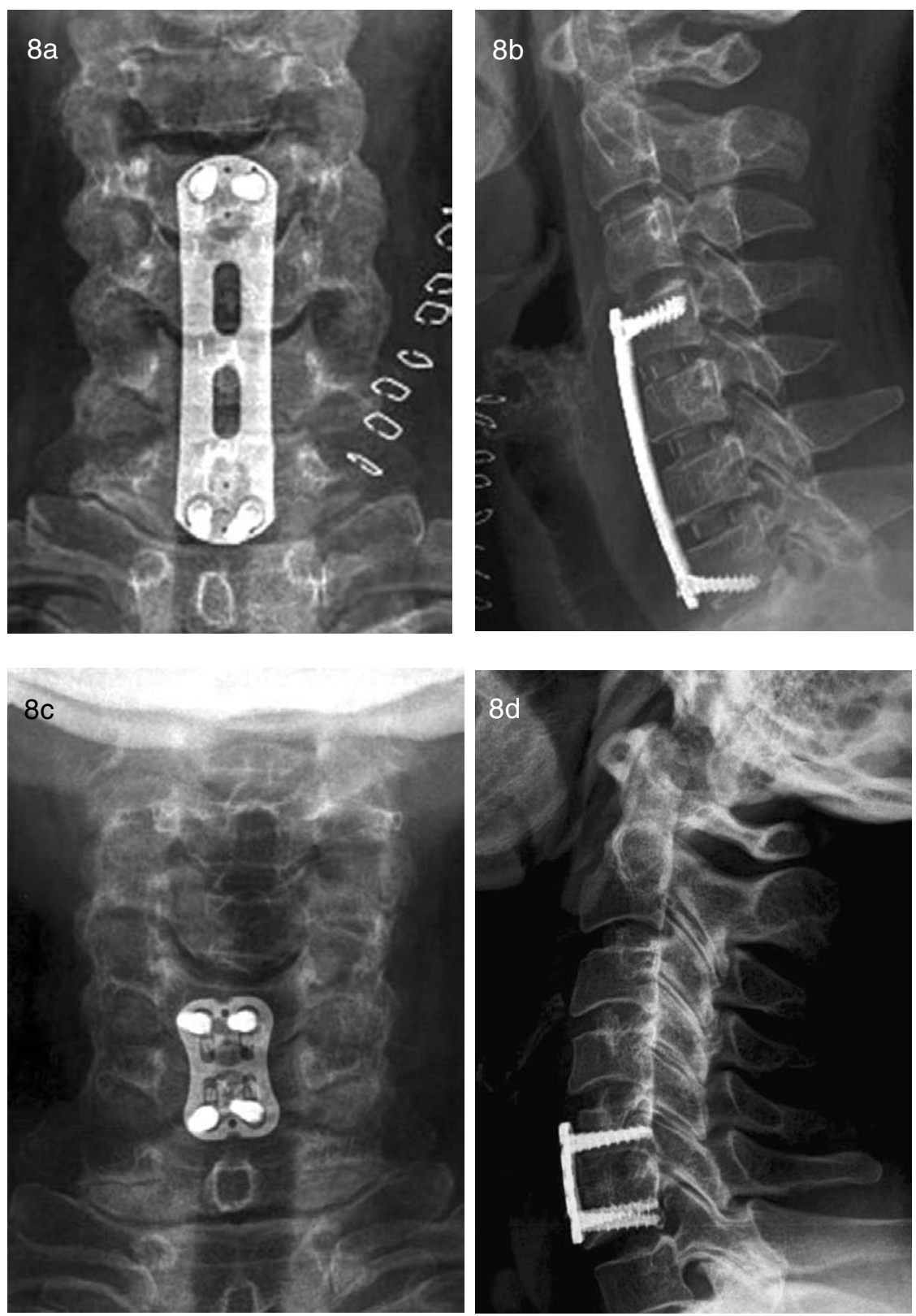

Figura 8. Placas cervicales anteriores. Discectomías en enfermedad degenerativa complicada; radiografías AP-L en: $(a, b)$ Fijación multisegmentaria entre C4 y C7 estabilizada con placa anteriory tornillos corporales. Cajas inter-somáticas. $(c, d)$ Discectomía unisegmentaria C5-C6 estabilizada con placa anterior y tornillos corporales; injerto óseo autólogo asimilado. 

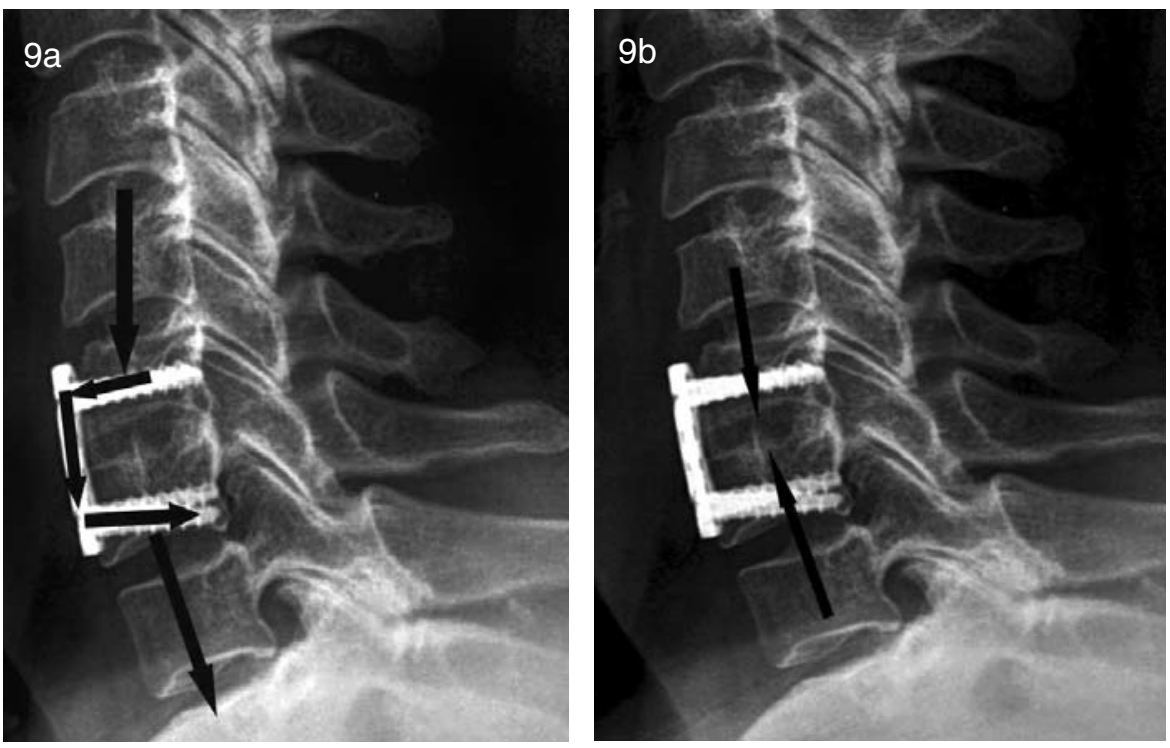

Figura 9. Mecanismo de acción de las placas cervicales anteriores. Placa rígida. (a), las fuerzas axiales principales siguen el trayecto de las flechas negras, haciendo un puente al injerto óseo a través de los tornillos y de la placa, con efecto escudo sobre éste. Ello puede retardar la asimilación del injerto o producir pseudo artrosis, al disminuir o evitar el contacto injerto-vértebras. Placa dinámica (b), la mayor parte de la carga axial se transmite a través del injerto, pues los tornillos tienen movilidad axial y angular en el agujero de la placa, manteniendo carga suficiente sobre el injerto, con menos posibilidades de rechazo o pseudoartrosis.
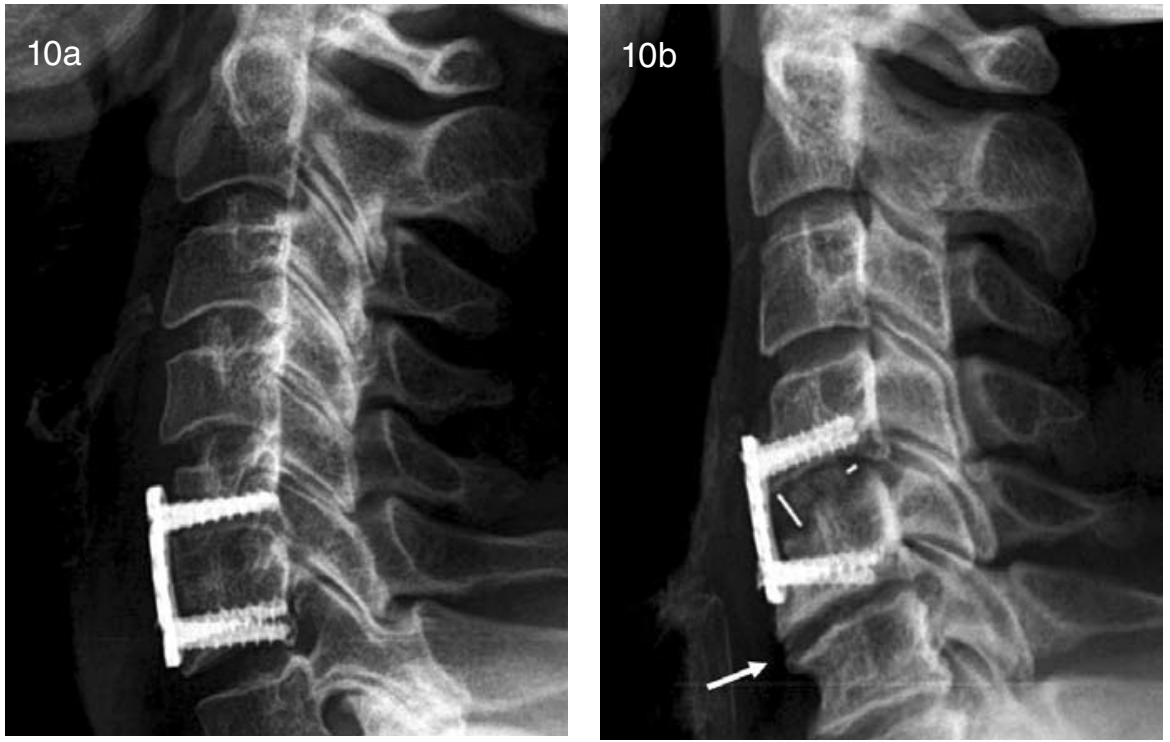

Figura 10. Asimilación de injertos óseos. Asimilación completa (a) con paso de trabéculas a los cuerpos vertebrales, sin interfase radiolúcida. Asimilación incompleta (b), injerto en caja intersomática, con interfases radiolúcidas que son más notorias en el borde superior. Nótese cambios degenerativos del segmento adyacente inferior (flecha).
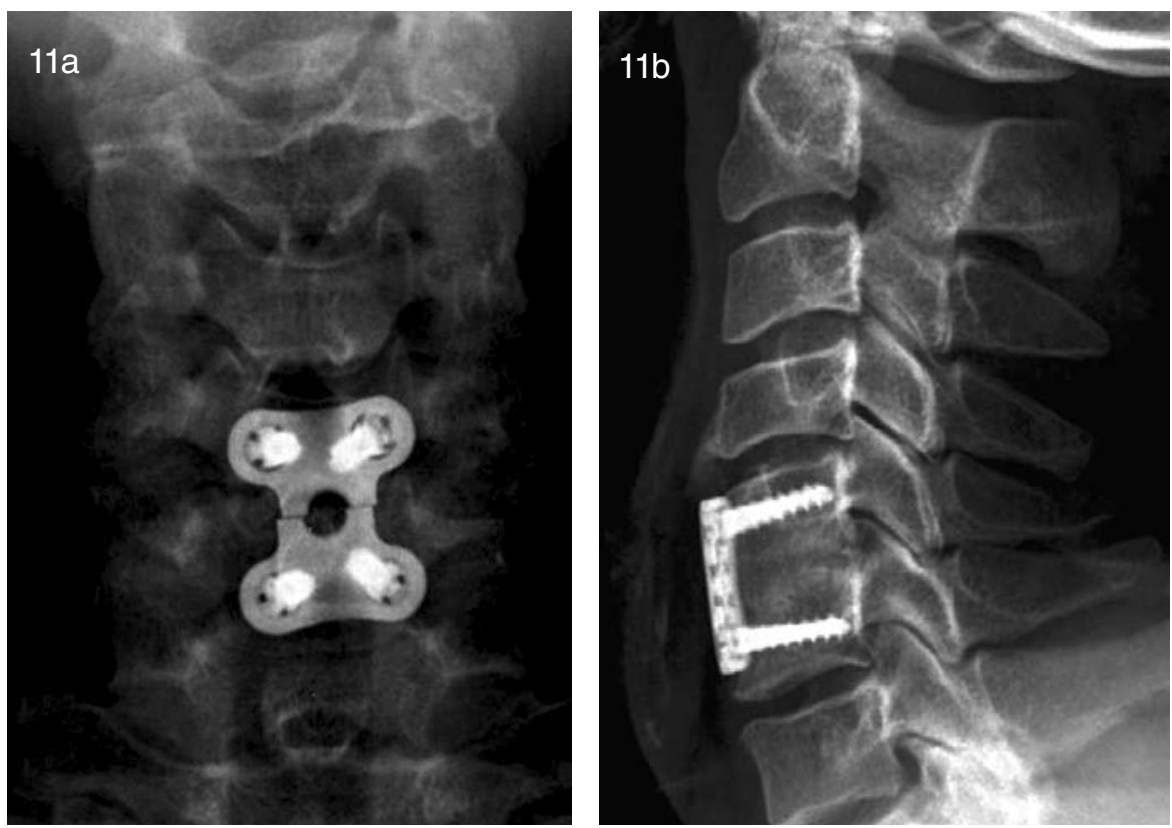

Figura 11. Dinamismo positivo (a, b) La falla del implante, con rotura de placa, en ciertos casos, permite transmitir al injerto fuerzas de carga axial, estimulando su incorporación, pese a la falla, evitando el rechazo, como se muestra aquí. 
Los llamados "cambios de los segmentos adyacentes" secundarios al uso de placas cervicales anteriores, despiertan controversia. La prevalencia global de los cambios degenerativos en los segmentos adyacentes (cambios radiográficos en los niveles adyacentes al de la fusión) ha sido estimada en $25 \%$ y la de enfermedad del segmento adyacente (síntomas clínicos nuevos que corresponden a cambios radiográficos adyacentes al nivel de la fusión) es del $9 \%$. Las fusiones multisegmentarias tienen menos enfermedad del segmento adyacente que las unisegmentarias ( $12 \%$ vs $18 \%)$; no esta claro aún si son el resultado de la fusión espinal o si es la progresión de la historia natural de la enfermedad degenerativa subyacente $^{(20)}$ (Figura 12).

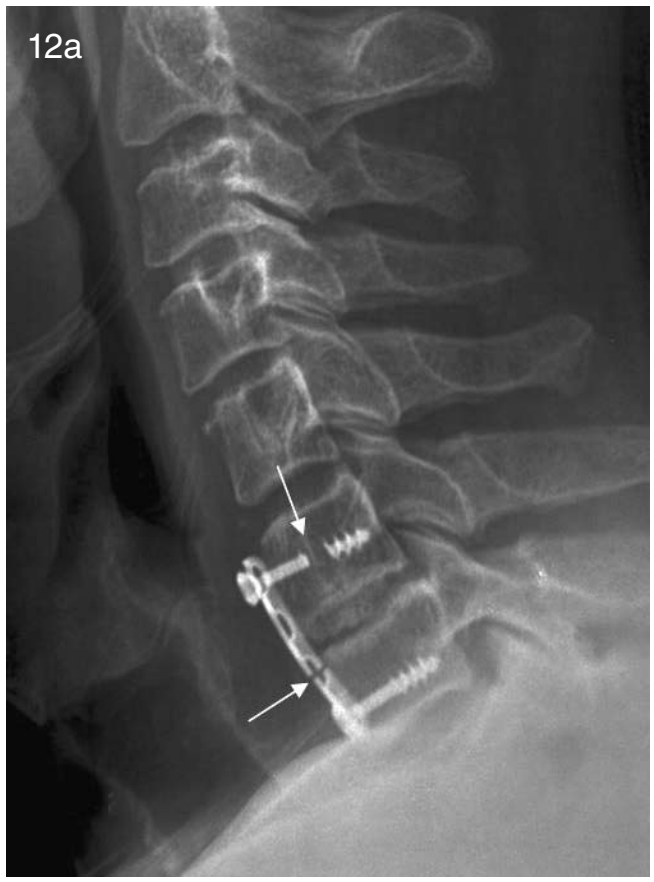

Figura 12. Complicaciones de las fijaciones. Rotura de placa y tornillo (flechas) (a) Subsidencia excesiva por falla del implante, con mala asimilación del injerto óseo, con interfases radiolúcidas injerto-vértebras y reducción de tamaño por desplazamiento. Rotura de placa (flecha corta) (b) La reabsorción del injerto produce la falla de la placa. Cambios degenerativos adyacentes en C3-C4 y C4-C5 (flechas largas). Osificación peri placa. (c) Si la placa queda muy cerca $(<5 \mathrm{~mm})$ del espacio discal adyacente (flecha delgada) puede inducir la aparición de osificaciones peri-placas (flecha gruesa) que pueden ser sintomáticas. Nótese cambios degenerativos del segmento adyacente.

\section{Cajas cervicales}

Se utilizan en enfermedad degenerativa uni o multisegmentaria. Estabilizan en todas las direcciones adecuadamente, excepto en extensión. Existen diferentes tipos, de distintos materiales y formas.
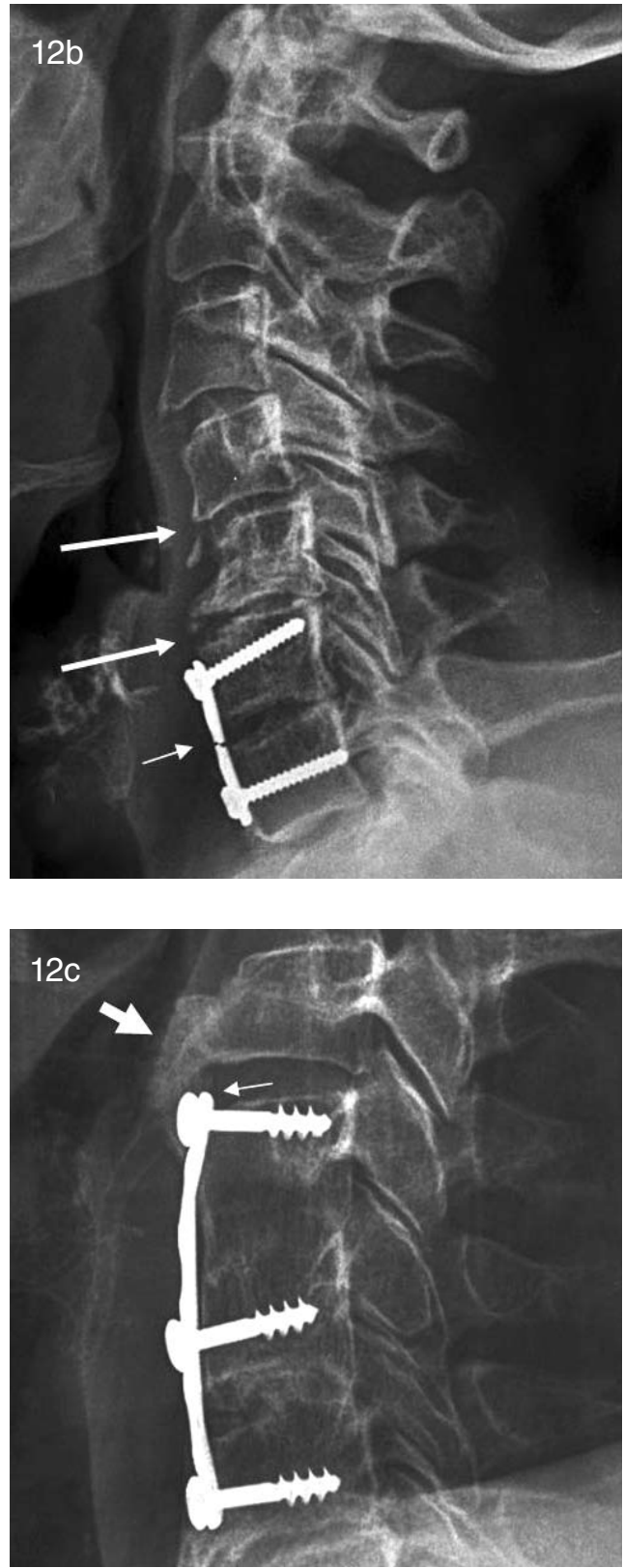

Las primeras fueron las cajas de titanio, para dar distracción al segmento operado por más tiempo que los injertos óseos, con mejor fusión (Figura 13). Las más utilizadas en la actualidad son de polímeros, polieteretercetona (PEEK), radiotransparentes y con líneas de titanio para ser visualizadas en las radiografías ${ }^{(21-23)}$ (Figura 14).

Los resultados publicados son buenos; la mayoría de las fallas son dificultades técnicas en la colocación del implante o selección inadecuada de los pacientes. Se han descrito los signos radiográficos en la evaluación postoperatoria de la fusión con cajas metálicas, tanto normales como con complicaciones; sin embargo, su exacta evaluación radiográfica es un desafío aun no resuelto ${ }^{(23-25)}$ (Figura 15). 

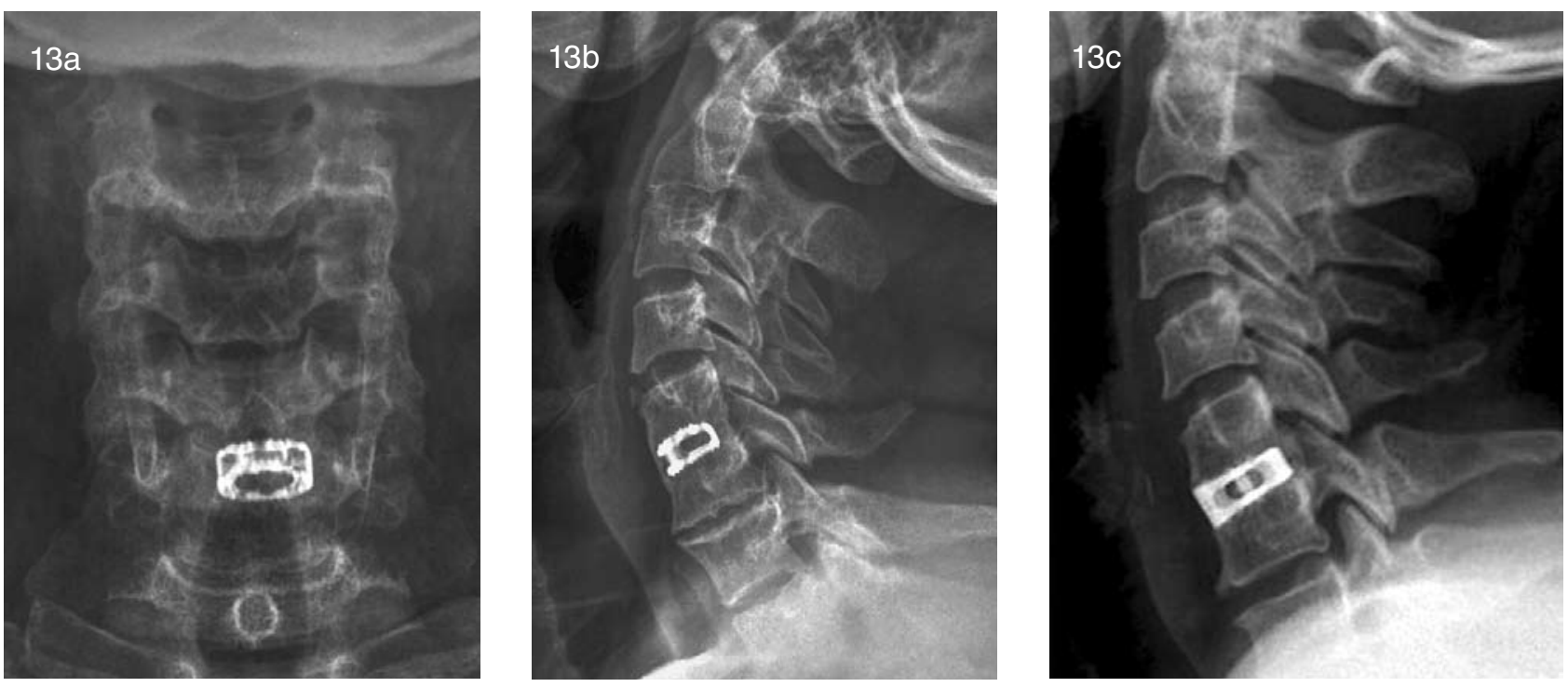

Figura 13. Cajas intersomáticas de titanio. Radiografías AP-L $(a, b)$ con caja intersomática de titanio C5-C6 en hernia discal tratada. Son dentadas para sujeción adecuada a los cuerpos vertebrales. En su interior contiene los injertos óseos. Radiografía $L$ (c) que muestra otro tipo de caja intersomática de titanio.
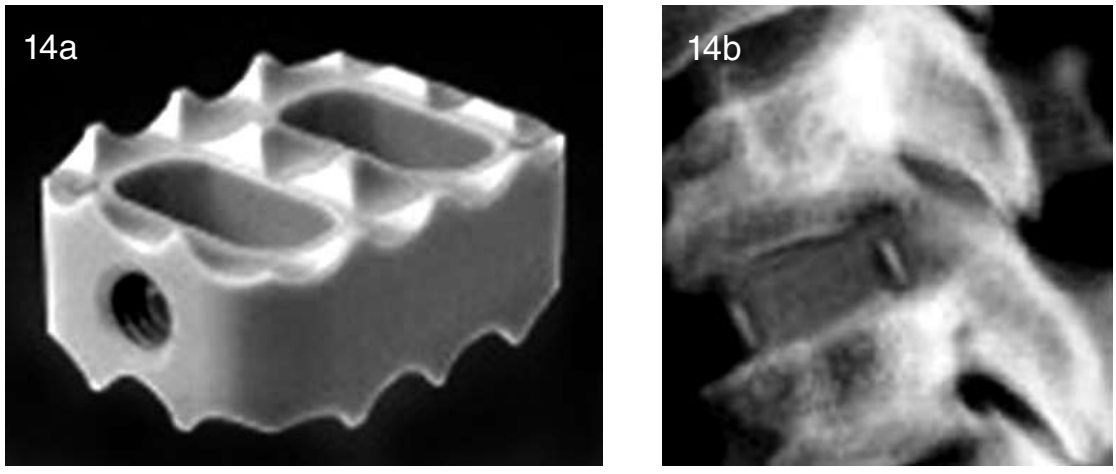

Figura 14. Cajas intersomáticas de polieteretercetona (PEEK). Fotografía (a) de una caja PEEK (RBEAR PEEK TSI) con superficie dentada para anclaje y fenestraciones para facilitar osteointegración. Radiografía lateral localizada (b) con caja intersomática C6-C7 en discectomía por hernia discal. Marcadores de Ti para fácil identificación y posicionamiento. Radiografía lateral (c) de otro paciente con discectomías y cajas PEEK C5-C6 y C6-C7, con marcadores de Ti puntiformes.
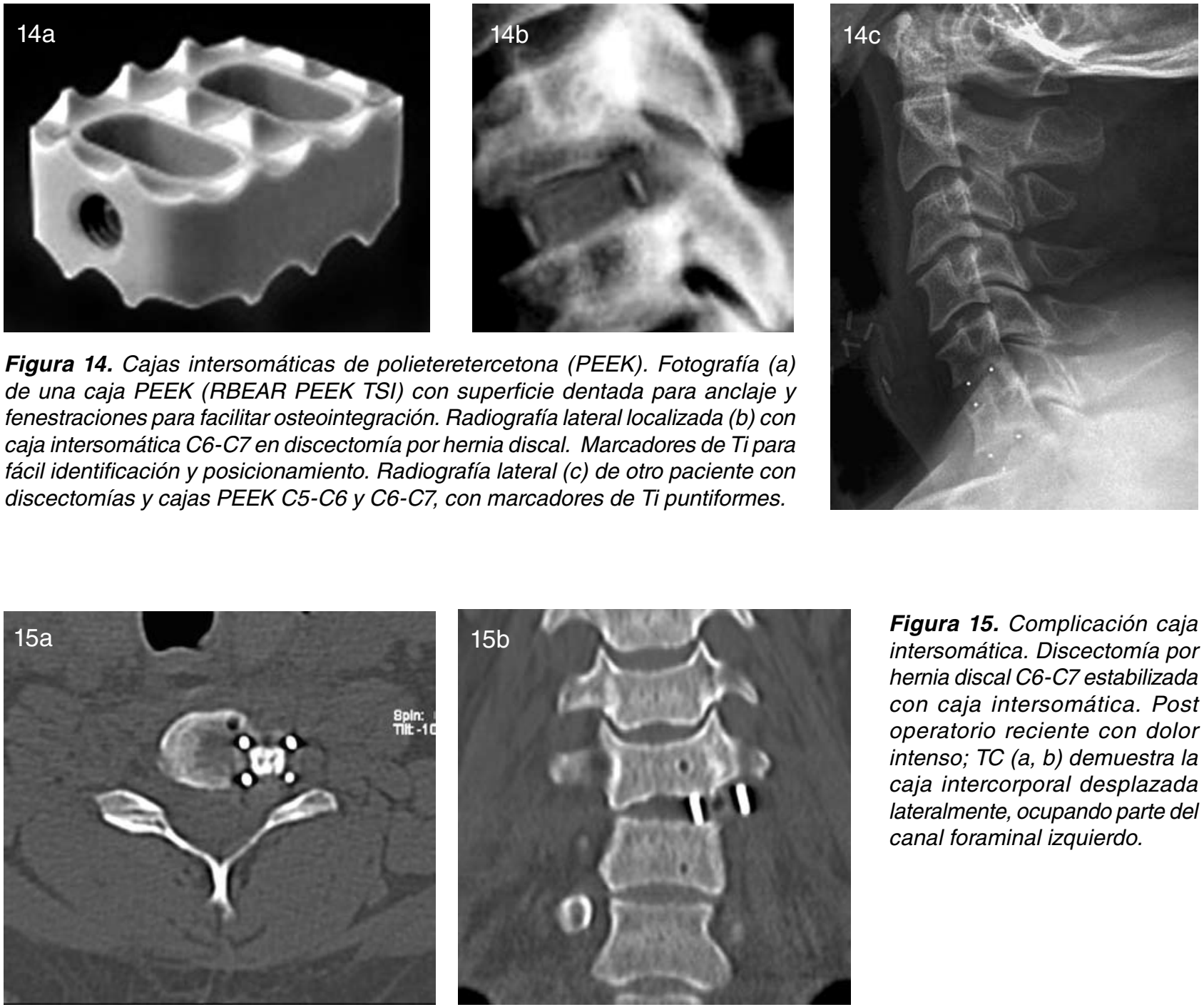

Figura 15. Complicación caja intersomática. Discectomía por hernia discal C6-C7 estabilizada con caja intersomática. Post operatorio reciente con dolor intenso; TC $(a, b)$ demuestra la caja intercorporal desplazada lateralmente, ocupando parte del canal foraminal izquierdo. 
En enfermedad no degenerativa (trauma, metástasis, infección) se han utilizado cajas cilíndricas expansibles, fáciles de insertar, con poco daño de la placa terminal y adecuada mantención/aumento de la distracción. Los resultados preliminares publicados describen mejorías objetivas del dolor, sin subsidencias significativas, siendo adecuadas para la reconstrucción cervical y la corrección del mal alineamiento sagital. Se trata de resultados preliminares y requieren estudios sistemáticos de validación para situar su rol el en el contexto clínico y sus indicaciones precisas ${ }^{(26)}$ (Figura 16).

\section{Placa-caja}

El sistema placa-caja reúne los requerimientos biomecánicos de cada uno de sus componentes, la placa es de menor tamaño, con sólo un tornillo por cuerpo vertebral. La caja incluye injertos o biomateriales requeridos. La literatura comunica que la combinación placa-caja mejora sustantivamente los resultados obtenidos con injertos óseos intersomáticos y con el injerto con placa cervical anterior, aunque se han descrito algunas complicaciones ${ }^{(27)}$ (Figuras 17, 18).

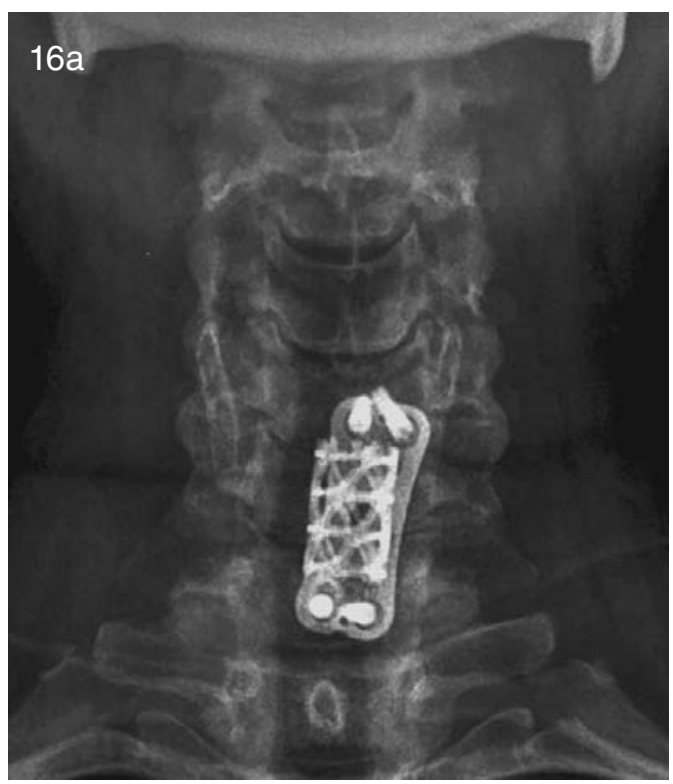

Figura 16. Caja expansible. Radiografías $A P-L(a, b)$, corporectomía parcial de C6, estabilizada con caja expansible tipo MESH en el sitio de la ectomía que mantiene la carga axial. Placa anterior y tornillos corporales a C5 y C7.
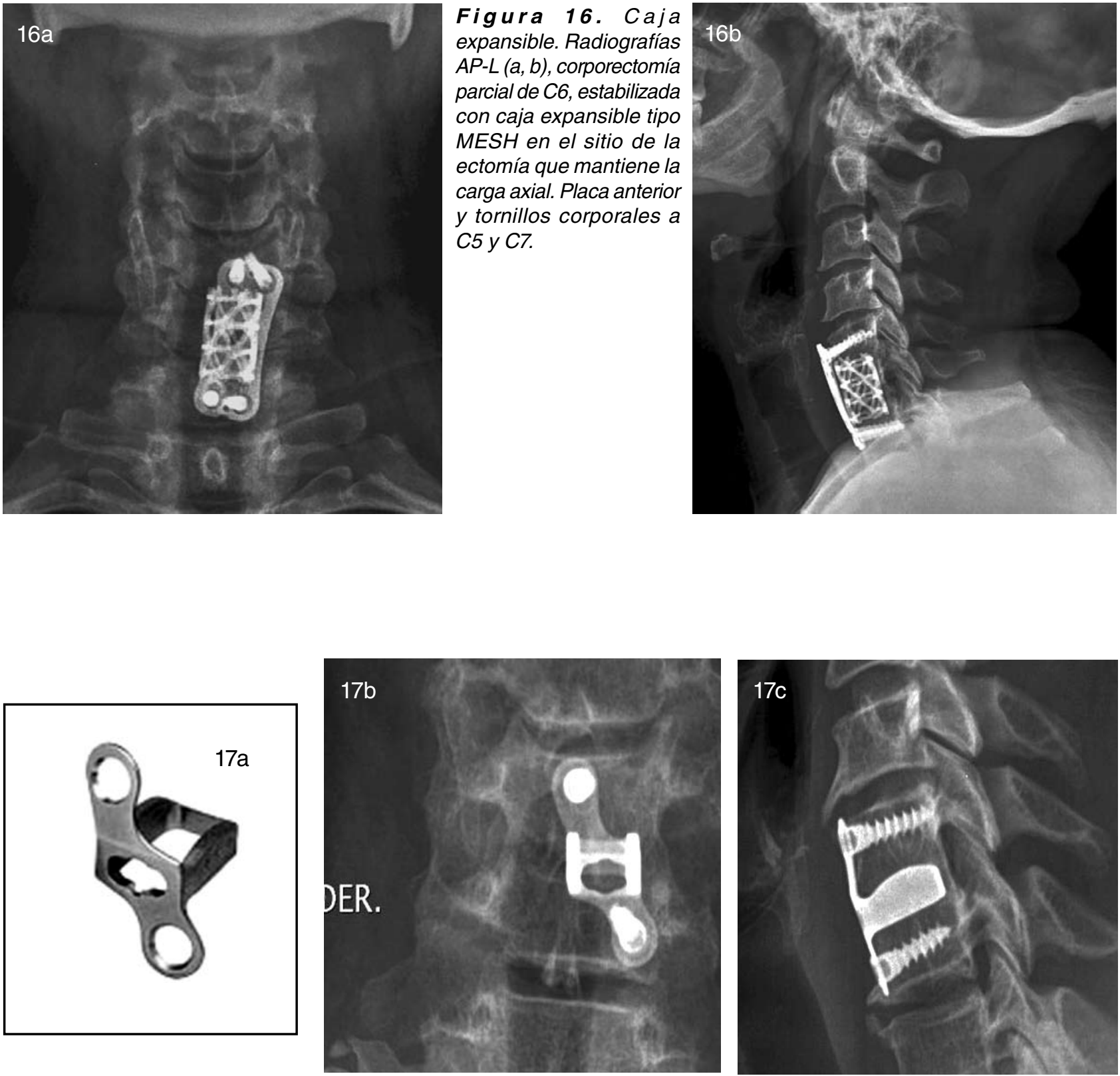

Figura 17. Caja-placa. Fotografía de caja-placa (a), la placa posee agujeros para los tornillos corporales y una caja destinada a ocupar el interespacio, donde se colocan los injertos óseos Radiografías AP- L (b, c), discectomía C5-C6 estabilizada con caja-placa anterior. Placa en diagonal fijada con un tornillo corporal en C5 y otro en C6. 

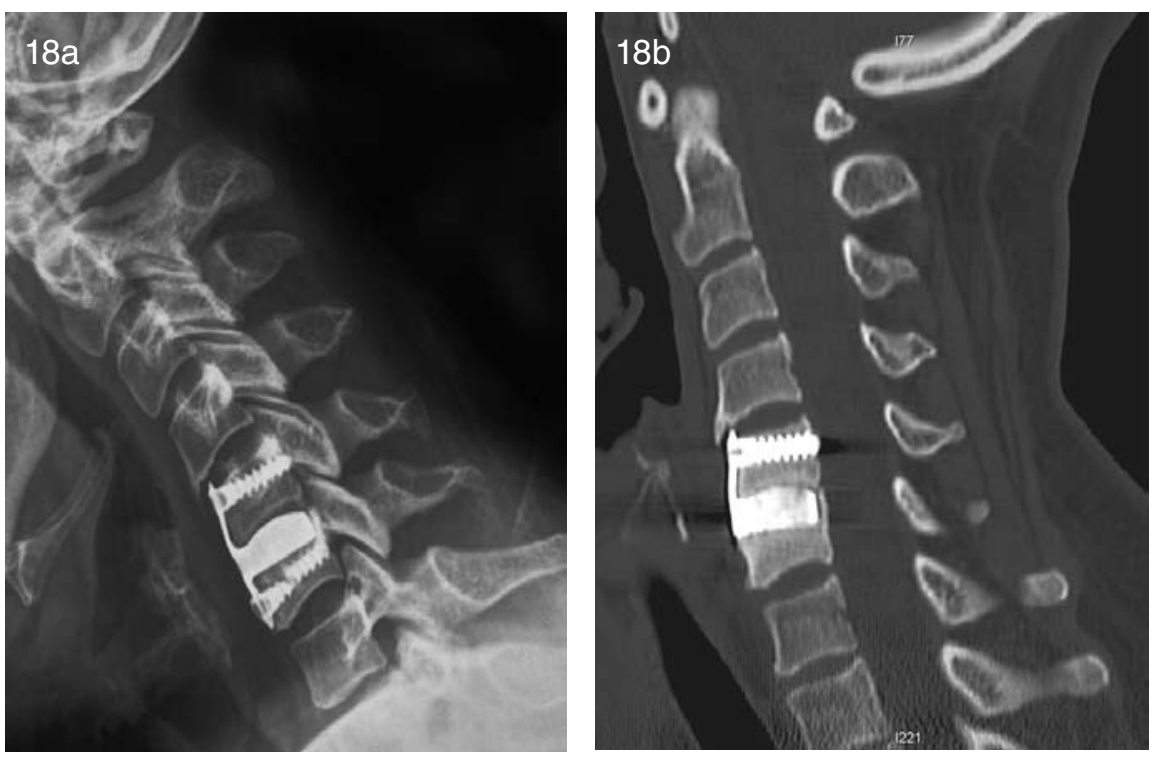

Figura 18. Complicación cajaplaca. Radiografía lateral (a) y reconstrucción sagital de TC (b). Discectomía C5-C6 estabilizada con placa-caja anterior y tornillos corporales anclados en C5 y C6. La caja ha comprimido la superficie craneal de C6 por subsidencia excesiva, fracturando el tornillo caudal al superar su capacidad de acomodación.

\section{Injertos óseos y biomateriales}

Los injertos son adyuvantes biológicos de la consolidación, no son implantes.

Los injertos óseos autólogos se emplean en la mayoría de las discectomías y fusiones anteriores, junto con sistemas de estabilización. Se usa un segmento tricorticado de cresta ilíaca, que reemplaza el disco removido. En discectomías de un solo nivel se pueden usar como elemento único de reemplazo. Las tasas de fusión con los injertos autólogos superan el $95 \%$ para las fusiones uni y multisegmentarias. La obtención del injerto tiene morbilidad: dolor y/o hematomas del sitio donador, infección y otros. Los injertos de banco son huesos desecados y congelados de cadáveres, esterilizados para prevenir la transmisión de enfermedades, proceso que destruye las moléculas que estimulan el crecimiento óseo (proteínas óseas morfogenéticas) con lo que los porcentajes de fusión son menores que con injertos autólogos (90\% en fusión única y $72 \%$ en más de un nivel ${ }^{(28-30)}$ (Figuras 19 y 20).

Los sustitutos sintéticos incluyen un amplio rango de materiales con variados efectos en la consolidación ósea y muchos de ellos están disponibles comercialmente. Existen tres grupos primarios de sustitutos óseos: matriz ósea desmineralizada (fundamentalmente osteoinductivas), cerámicas (sólo osteoconductoras) y materiales compuestos o combinados (incorporan la osteoconductividad de las cerámicas y las propiedades osteoinductivas de la matriz ósea desmineralizada en un compuesto único); son una amplia gama de presentaciones físicas con distintos componentes en su formulación ${ }^{(31,32)}$.

Tal diversidad puede confundirnos, siendo necesario clarificar el problema en base a la evidencia disponible. Están pendientes los estudios prospectivos controlados y randomizados para tener evidencia confiable con su empleo ${ }^{(33)}$.
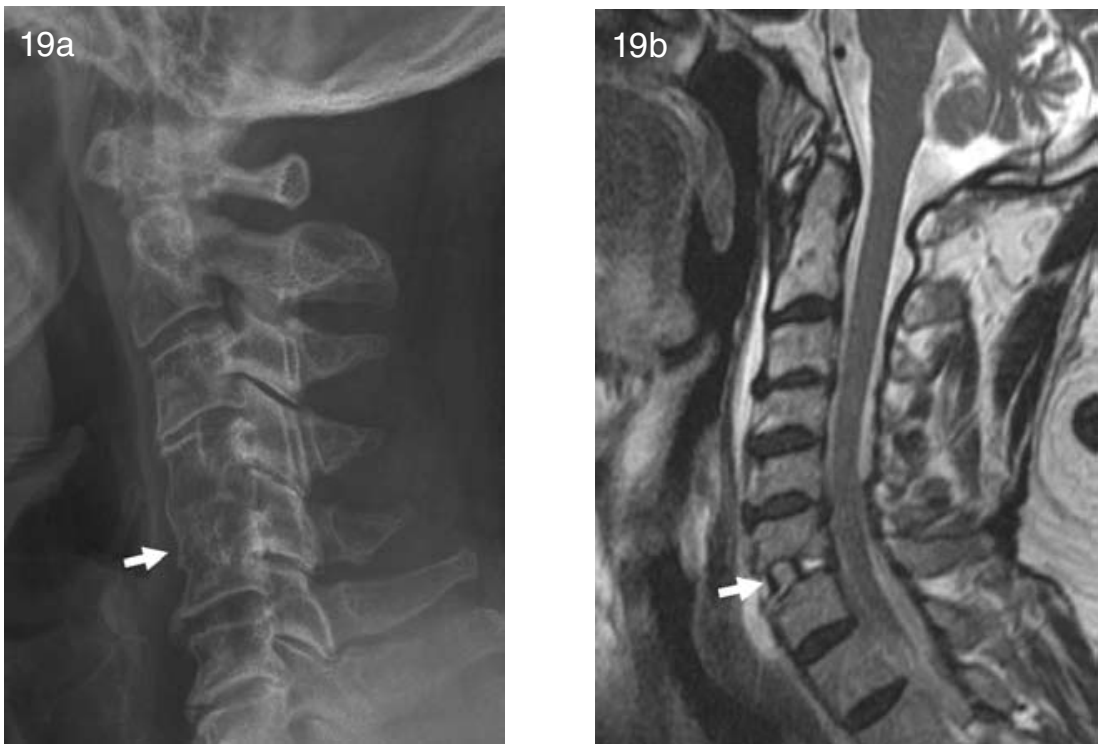

Figura 19. Injertos óseos intersomáticos. Radiografía lateral (a), discectomía C5C6 estabilizada con injerto óseo autólogo íntersomático asimilado: hay paso de trabéculas hacia los cuerpos vertebrales y no se observa interfase radio lúcida entre injerto y cuerpos vertebrales (flecha). Secuencia sagital de RM (T2 FSE) (b) de otro paciente, muestra el injerto óseo corticado asimilado situado en el espacio intervertebral, de señal normal (flecha). 

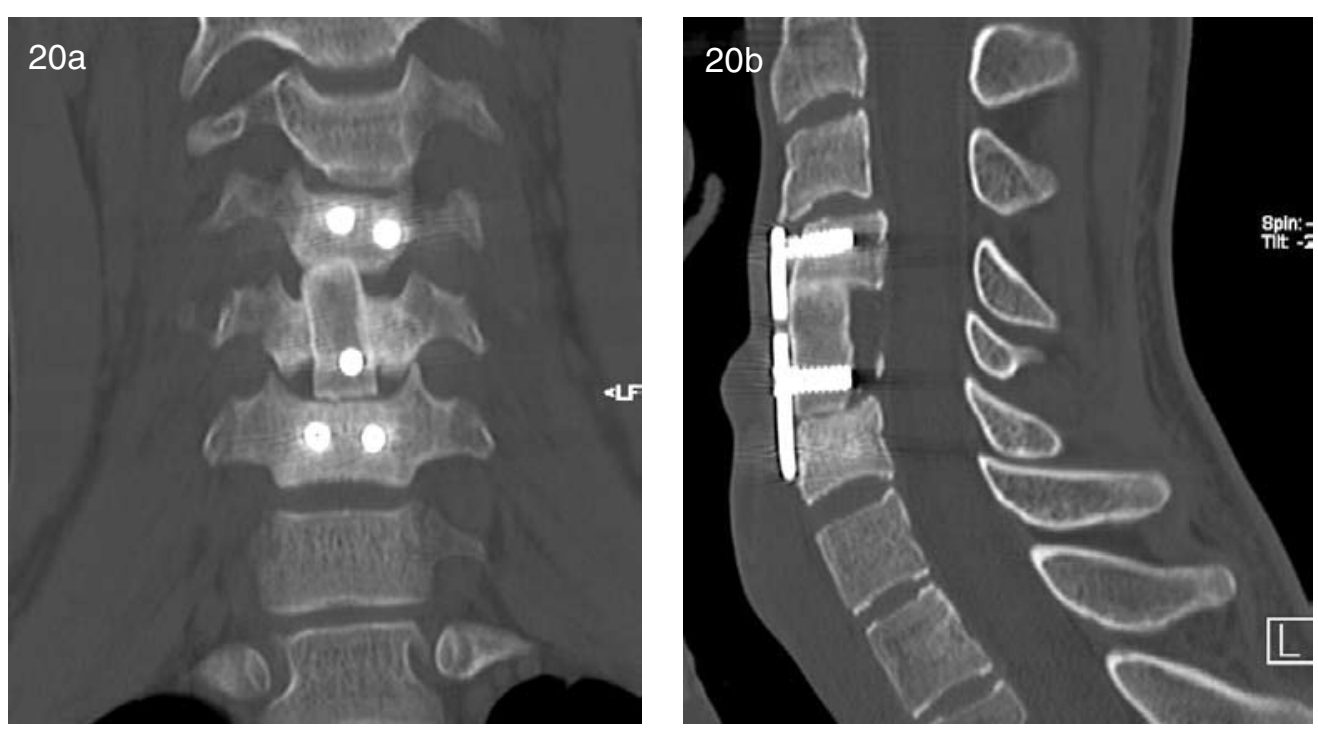

Figura 20. Injerto óseo estructural. Reconstrucciones sagitales de TC (a, b) en paciente con fractura conminuta de C5. Hemicorporectomía estabilizada con placa anterior fijada con tornillos corporales en C4 y C6. Nótese el injerto óseo estructural con hueso de banco fijado con tornillo a la placa, que ocupa parte de la resección.

\section{B) Fijaciones posteriores}

Se han utilizado un sinfín de elementos de fijación posterior: alambres, cables, ganchos, distintos tipos de placas y otros. En la actualidad, existe la tendencia al uso de barras fijadas con tornillos transpediculares para tratar las inestabilidades derivadas de lesiones traumáticas o neoplásicas de los elementos medios y posteriores de la columna cervical subaxial ${ }^{(34,35)}$ (Figura 21).

\section{C) Fijaciones combinadas}

Esta aproximación se utiliza cuando hay lesiones de muros anterior y posterior, generalmente traumáticas, abordajes que pueden ser simultáneos o diferidos.

En la fijación anterior se utilizan por lo general placas y en la posterior barras y tornillos transpediculares $^{(3)}$ (Figuras 22, 23).

\section{Artroplastias cervicales}

Indicadas en radiculopatías y mielopatías secundarias a protrusiones discales agudas o a espondilosis degenerativa, uni o multisegmentarias sin respuesta al tratamiento médico adecuado. No resisten inestabilidades translacionales, por lo que están contraindicadas en todo tipo de ántero-listesis, en laminectomías y trauma. Se pueden utilizar en columnas con artrodesis previas ${ }^{(36-38)}$.

Preservan el movimiento de la columna, previniendo las complicaciones asociadas a las artrodesis rígidas, por la pérdida segmentaria de la movilidad. Eliminan la morbilidad del sitio donador de los injertos óseos autólogos y las posibles complicaciones infecciosas de los huesos de banco. Además, disminuirían la incidencia de cambios degenerativos del segmento adyacente.

Se ha descrito que un porcentaje, que ha ido disminuyendo, termina en fusión, ya sea por migración tardía y grados variables de subsidencia (dependiendo del tipo de prótesis), por osificación heterotópica que disminuye la movilidad en diferentes grados o por fusión de la artroplastia, en pocos casos ${ }^{(39,40)}$.

Las prótesis discales actuales datan de fines de los años 80, con la prótesis de Cummins-Bristol, con muchas complicaciones derivadas de su tamaño único y de problemas con la fijación de los tornillos. En la actualidad, hay al menos cinco sistemas de artroplastía en uso clínico, distintos en cuanto a materiales (polímeros de polietileno o poliuretano de ultra alto peso molecular, aleaciones de titanio, cromo-cobalto y otros), rango de movimientos, técnica de inserción y limitaciones ${ }^{(41,42)}$ (Figuras 24-30).

Las publicaciones de los resultados clínicos iniciales, especialmente en Europa, evaluando distintas prótesis, las tasas de complicaciones y su eficacia son similares a los de la cirugía de fusión. Los resultados a largo plazo no se han publicado aún y definirán las indicaciones si las complicaciones de la fusión se evitan y, más importante aún, si aparecen nuevas complicaciones asociadas a la preservación del movimiento ${ }^{(43,44)}$.

Las complicaciones precoces publicadas, aparte de las post operatorias (hematoma, disfagia, disfonía, escapes de LCR, persistencia de la sintomatología por descompresión inadecuada) son debidas a selección de la técnica quirúrgica inadecuada, con mal posicionamiento o falla del aparato(45) (Figuras 31, 32).

El desgaste del polietileno que puede llevar al aflojamiento aséptico de las artoplastías, está pendiente de evaluación. Estudios clínicos en prótesis lumbares no han demostrado hasta la fecha, que esto sea un problema importante; sin embargo, son estudios de corto plazo y se requiere mayor investigación para conclusiones válidas ${ }^{(46,47)}$

Es una tecnología en pleno desarrollo en cuanto a articulación y cinemática, integración/fijación, 

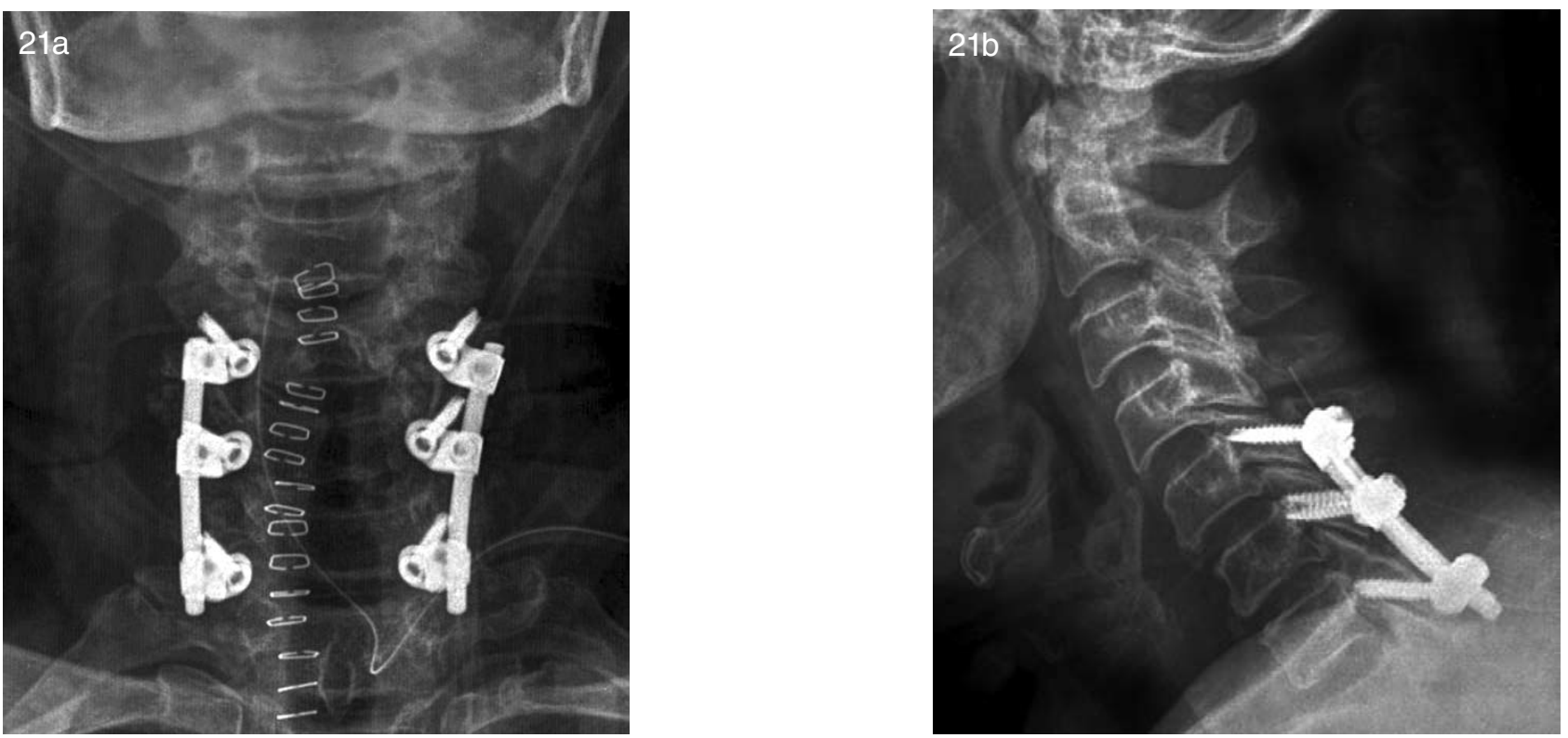

Figura 21. Fijaciones posteriores. Radiografías $A P-L(a, b)$, luxofractura facetaria y rotura de ligamentos posteriores. Estabilización con tornillos transpediculares con conectores ajustables a barras posteriores en C5, C6 y C7.
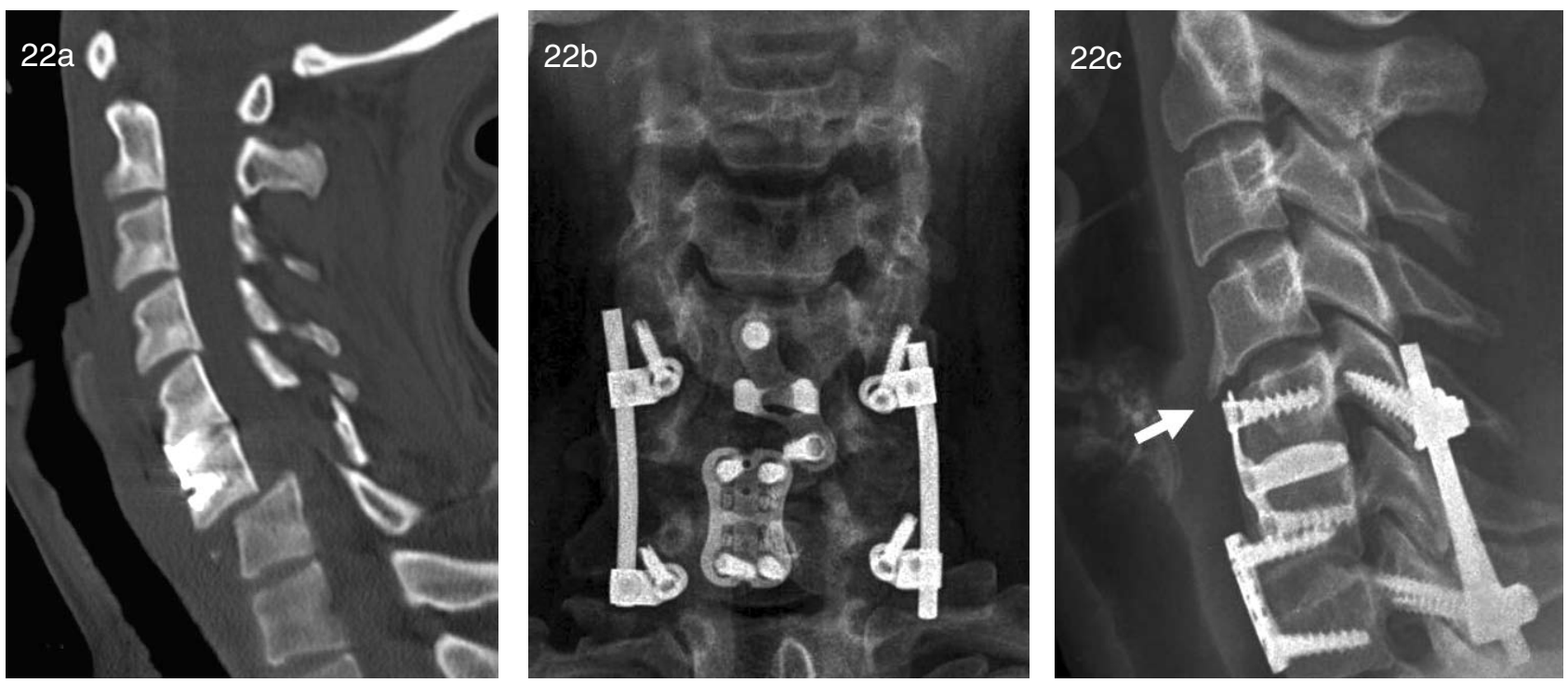

Figura 22. Fijaciones combinadas. Reconstrucción sagital de TC (a) que muestra una luxo-fractura C6-C7, con ánterolistesis post traumatismo. Placa-caja C5-C6 en discectomía previa. RM (no mostrada), pseudoprotrusión discal posterior, con conflicto de espacio medular. Radiografías AP-L post operatorias (b,c), estabilización posterior con barras verticales ancladas con tornillos transpediculares a C5 y C7. Estabilización anterior con placa fijada con tornillos corporales en C6 y C7. Discectomía antigua estabilizada con placa-caja C5-C6. Nótese osteofito que emerge de la cara antero inferior de C4 hacia caudal debido a colocación muy alta de la placa antigua (flecha).

nuevos materiales y diseños, ya que además de mantener el tipo y rango normal de movimiento deben transmitir la carga axial de un cuerpo vertebral al otro. No hay evidencias que definan a una de ellas como ideal. El futuro de las prótesis discales va a ser definido por el porcentaje de fusión espontánea en el tiempo, las limitaciones para recuperar las curvas alteradas, la tecnología intra operatoria y el costo de los implantes ${ }^{(48,49)}$.

\section{Evaluación post-operatoria con imágenes}

La caracterización de los hallazgos post operatorios con imágenes mejora con la comprensión de la biomecánica de la columna vertebral. La radiografía simple con proyecciones funcionales ha sido la modalidad estándar en la evaluación de los componentes de la artrodesis, donde los principales parámetros a evaluar son el estado de la fusión, la instrumentación, pseudoartrosis, cambios degenerativos, infección. 

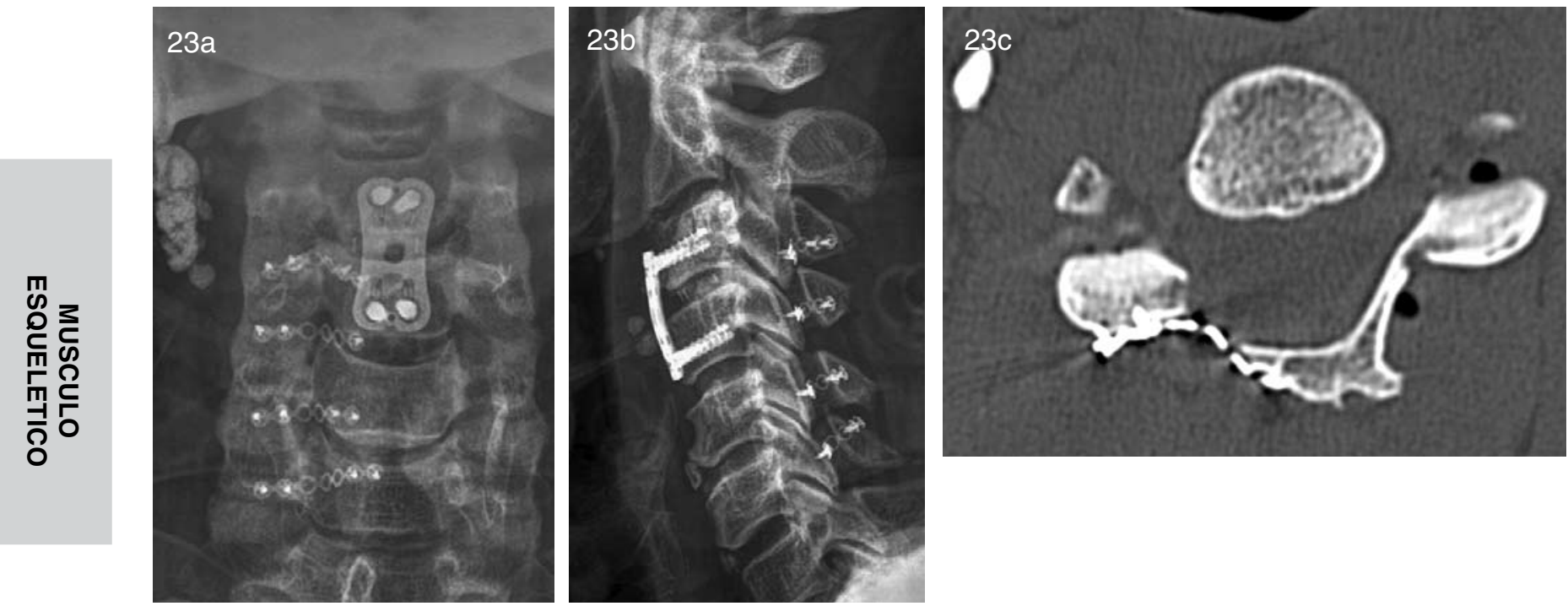

Figura 23. Radiografías AP-L (a,b) y corte axial de TC (c), raquiestenosis central C3-C4 y C4-C5 severa con mielopatía compresiva discal. Cirugía con laminectomías parciales derechas de C3 a C6, estabilizadas con miniplacas maleables y tornillos anclados a los bordes de sección. Discectomía diferida C3-C4 estabilizada con placa anterior, caja intersomática e injerto óseo. En TC, nótese adenopatías calcificadas y enfisema de partes blandas, post quirúrgico.

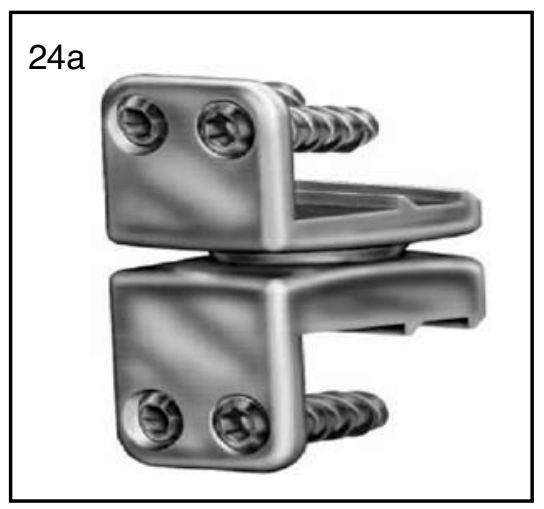

Figura 24. Prótesis discal. Fotografía (a) y Radiografía lateral (b) de prótesis CUMMINSBRISTOLR utilizada para tratar hernia discal C-C7. Consta de 2 piezas de acero inoxidable tipo "ball in socket", que se fija con tornillos a la cara anterior de los cuerpos vertebrales.
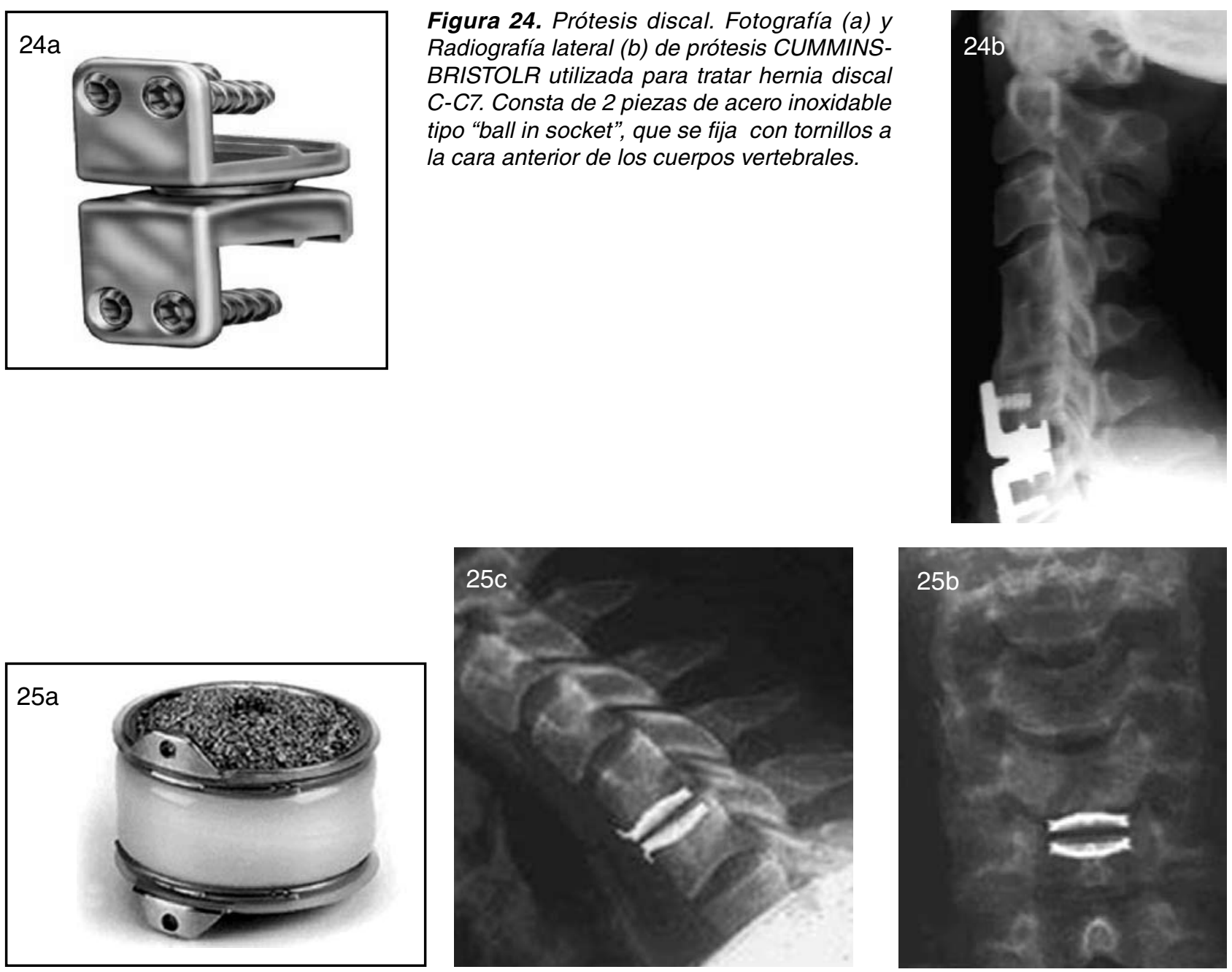

Figura 25. Fotografía (a) y radiografías AP-L (b,c), hernia discal complicada C5-C6 operada, con prótesis BRYANR (Medtronic Sofanor Danek, USA). Consiste de un núcleo de poliuretano entre dos placas convexas de aleación de titanio. 


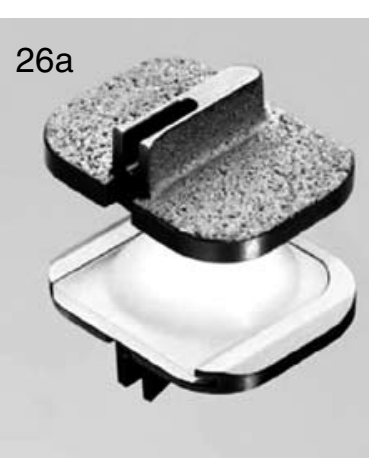

Figura 26. Fotografía (a) y radiografías $A P-L$ (b,c) Artroplastía C6-C7 en hernia discal complicada, con prótesis PRODISC-CR (Spine Solution, USA) Consiste en dos placas de Co, Cr y Mo, con un recubrimiento de Ti que contiene un núcleo de poliuretano entre las placas. Es un compartimiento cerrado para contener las partículas de desgaste.
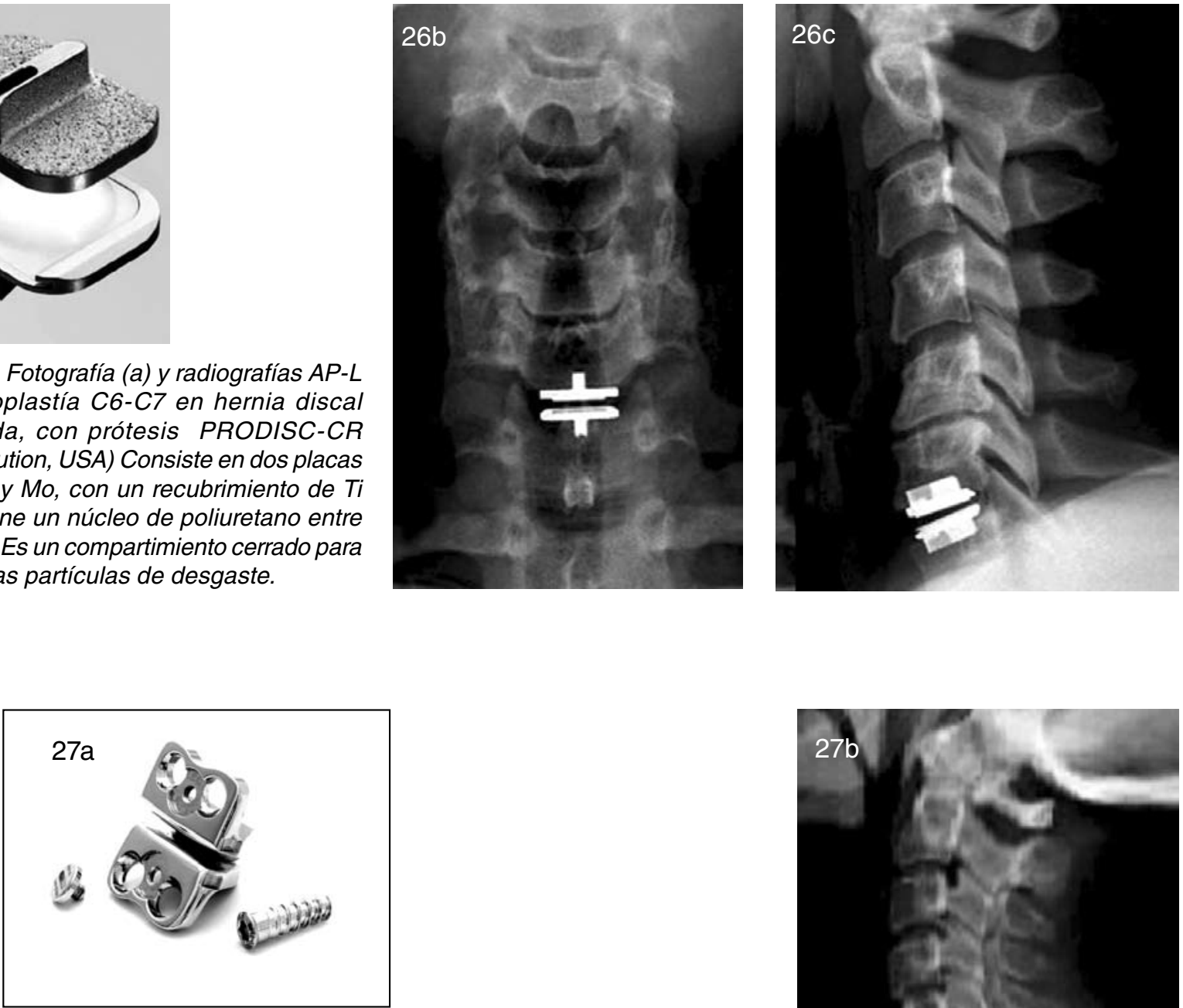

Figura 27. Fotografía (a) y radiografía lateral (b), discectomía C6-C7 con prótesis PRESTIGE STR (Medtronic Sofamor Danek, USA). Consiste en dos piezas de metal (carbidato de titanio) con elemento articulante entre ellas; fijadas con tornillos a los cuerpos vertebrales adyacentes.
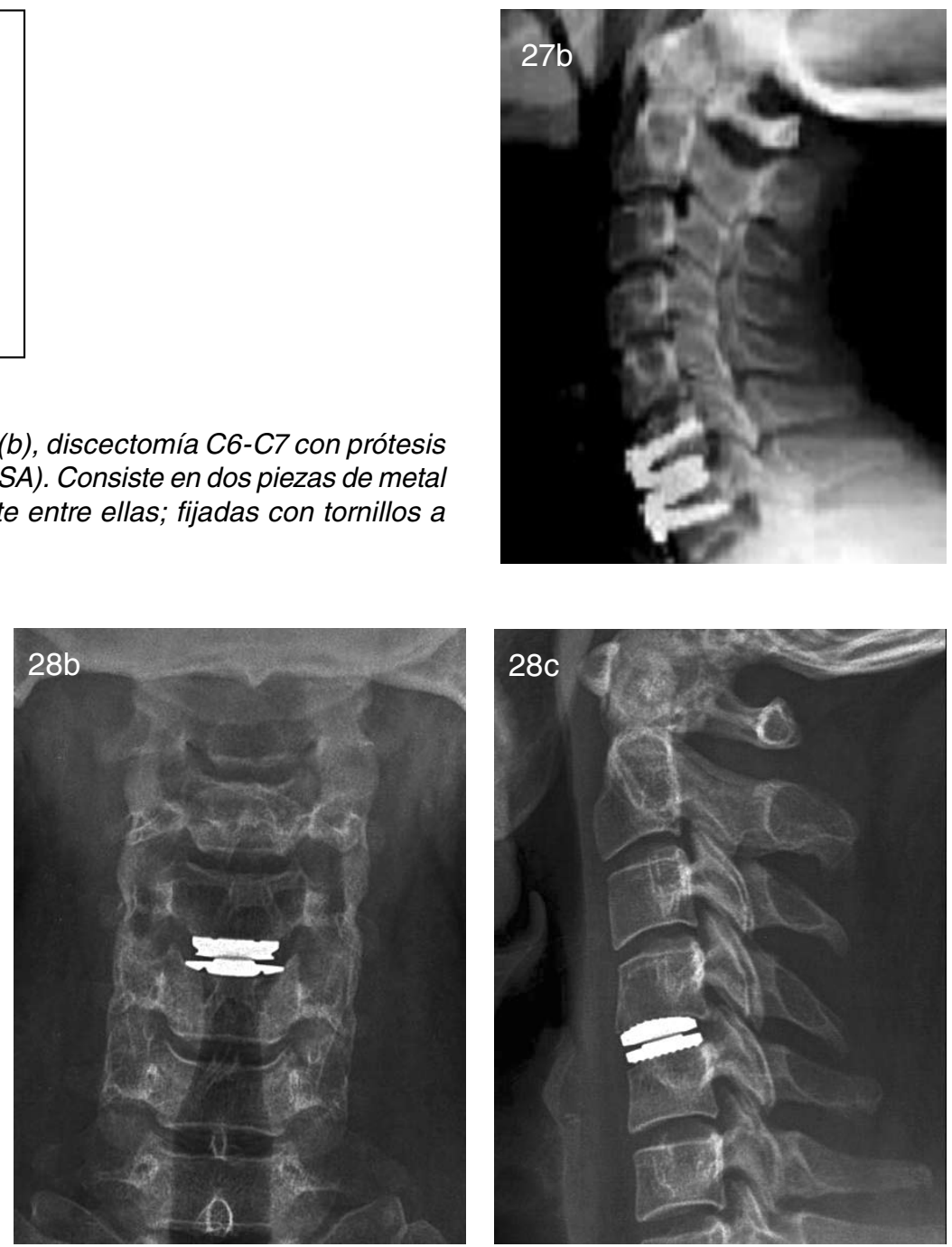

Figura 28. Fotografía (a) y radiografías AP-L (b,c), artroplastía C5-C6, con prótesis discal PRESTIGE STLPR (Medtronic Sofamor Danek, USA). Esta versión reciente permite el uso multisegmentario; no utiliza tornillos para su fijación. 

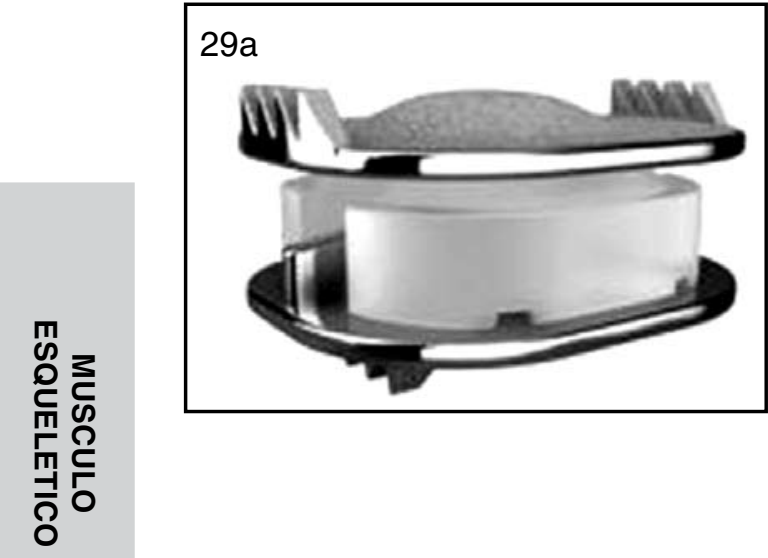
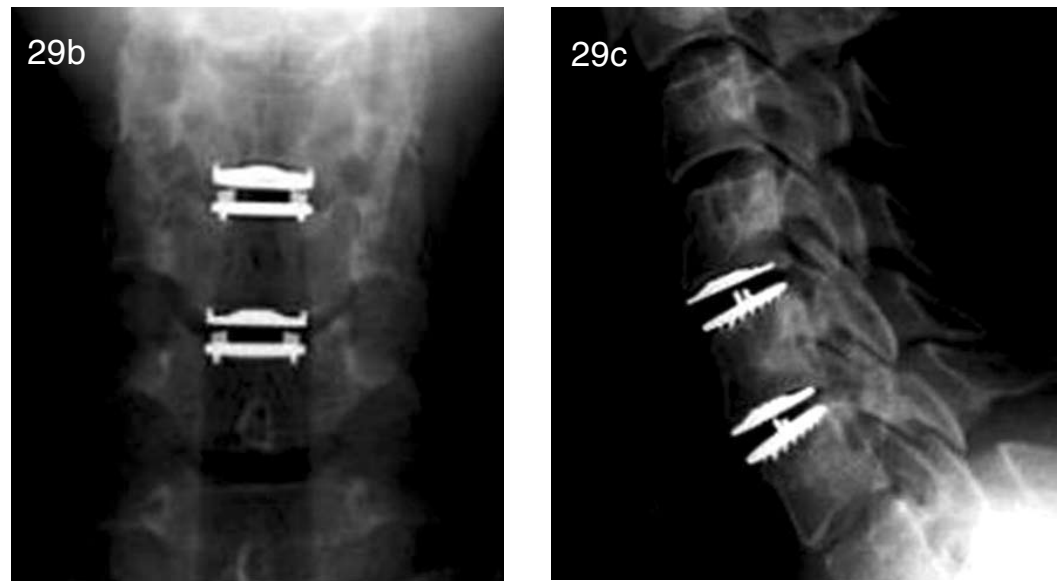

Figura 29. Fotografía (a) y radiografías AP-L (b,c), discectomías C4-C5 y C5-C6 con prótesis MOBI-C (The Mobi-CR $L D R$, Francia ). Consiste en dos placas de una aleación de Co, Cr y Mo y un inserto móvil interplacas, de polietileno de ultra alto peso molecular.
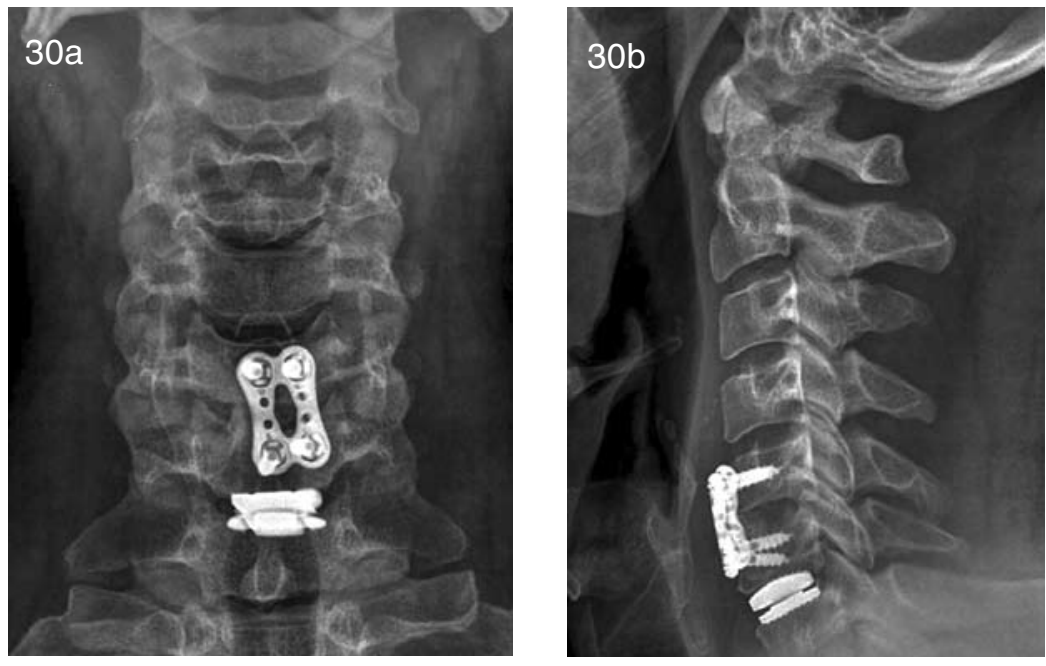

Figura 30. Uso combinado de artroplastía y artrodesis. Radiografías AP-L $(a, b)$, discectomía C6-C7 reciente con prótesis discal PRESTIGER STPL en hernia discal complicada. Nótese discectomía C5-C6 antigua, estabilizada con placa anterior $y$ tornillos corporales in situ.
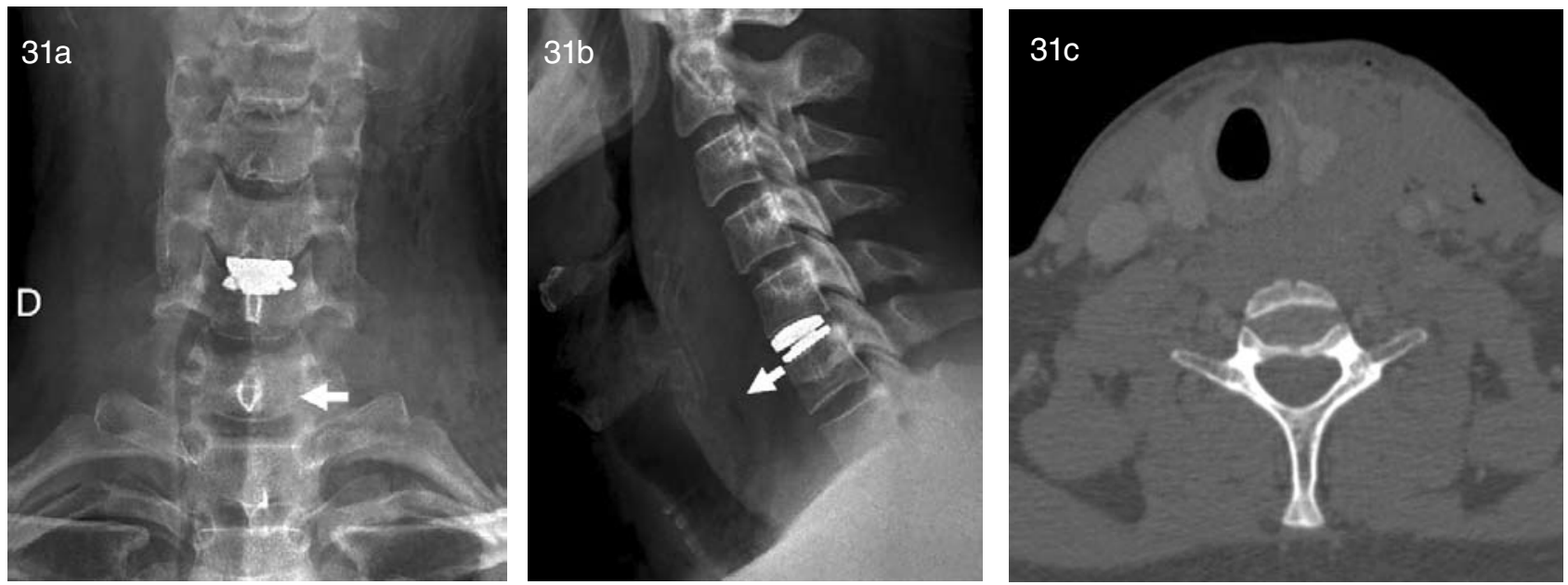

Figura 31. Complicaciones de las prótesis. Radiografías AP-L $(a, b)$ y TC (c), discectomía C5-C6 con prótesis bien situada. Nótese el aumento de volumen de partes blandas del espacio prevertebral que rechaza la vía aérea hacia anterior y lateral derecho (flechas), consistente con hematoma postoperatorio. 

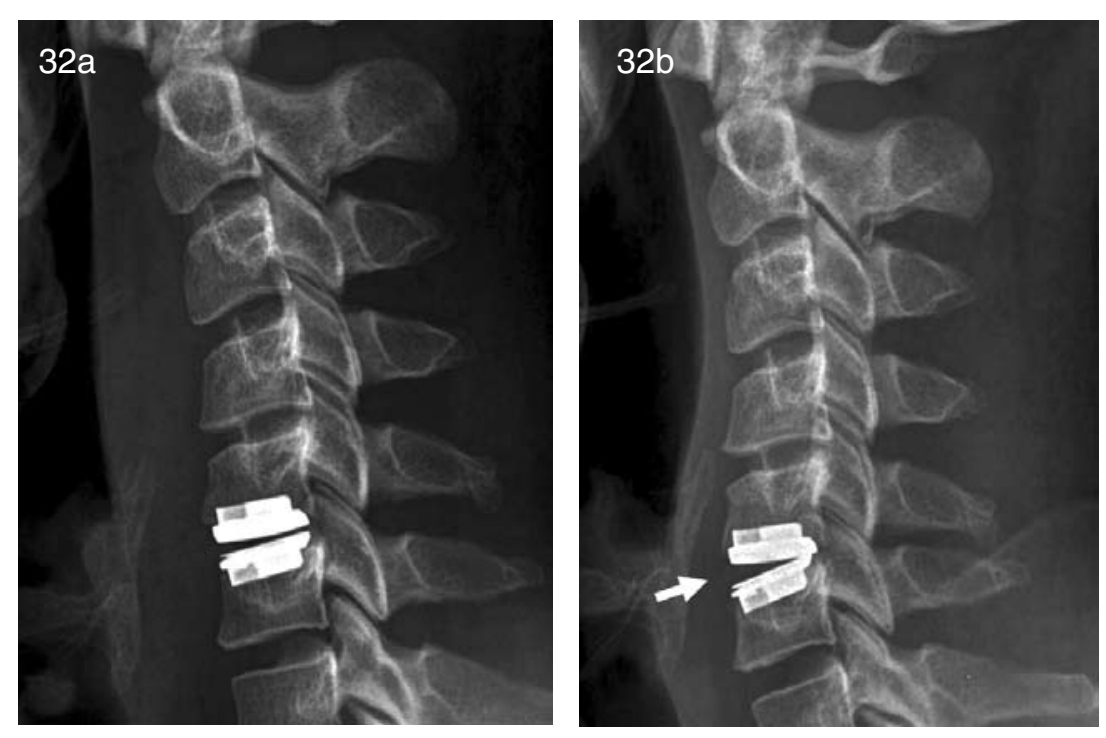

Figura 32. Complicaciones de las prótesis. Radiografía lateral (a) de artroplastía C5C6 con prótesis in situ. Cifosis proximal. Radiografía lateral (b) seis meses después, sintomático. Persiste la cifosis y hay pérdida del paralelismo de los componentes debido a subsidencia excesiva del componente inferior (flecha).

Evaluar la fusión no es fácil: el cruce trabecular se produce entre 6 a 9 meses post intervención. En radiografía simple con proyecciones funcionales, se considera inestabilidad por sobre $3 \mathrm{~mm}$ de deslizamiento. También se ha propuesto usar los criterios de Ray, una aproximación empírica de cajas lumbares, válida para columna cervical ${ }^{(50)}$.

La TC multicorte con reconstrucciones multiplanares es muy útil en la planificación pre-operatoria. En el post operatorio se usa para delimitar en forma detallada los elementos de fijación y los injertos o biomateriales.

La pseudoartrosis madura da una imagen radiolúcida nítida que cruza el injerto óseo; es difícil verla en radiografía simple, pero se delimita bien con TC. La pseudoartrosis inicial se evalúa bien con cintigrafía ósea y la TC permite estudiar el sitio de la captación aumentada. Si el constructo no tiene susceptibilidad magnética, se utilizan secuencias de RM con TR largo que muestran un aumento focal de la intensidad de la señal en la zona sospechosa.

Los cambios degenerativos del segmento adyacente se evalúan con radiografías simples, TC o RM para los cambios óseos, ligamentosos o discales que pueden llevar a nueva inestabilidad. Mínimas variaciones en la técnica quirúrgica pueden producir cambios desfavorables en el resultado: placas cervicales anteriores que sobrepasan en más de $5 \mathrm{~mm}$ el borde vertebral hacia el espacio intervertebral favorecen la formación rápida de osteofitos $^{(32,51-53)}$.

La infección se estudia con imágenes seccionales y es una complicación que puede ser tan tardía como dos años tras la cirugía.

En las artroplastías, el control post operatorio inmediato con radiografías evalúa la posición de la prótesis en el espacio intervertebral. En los controles tardíos, analiza el grado de incorporación y la movilidad de segmento operado.

Conociendo los tipos de aparatos, sus indicaciones generales, biomecánica, y complicaciones, además del motivo del examen actual (síntomas, tipo de aparato utilizado, etc.), el radiólogo estará en condiciones de evaluar las imágenes post-operatorias normales y patológicas, reconocer fracturas o rechazos de la instrumentación, mal posicionamiento e infección post-operatoria, especialmente en los pacientes sintomáticos, y confeccionar un informe radiológico útil y consensuado con el médico tratante (Esquemas 1 y 2 ).

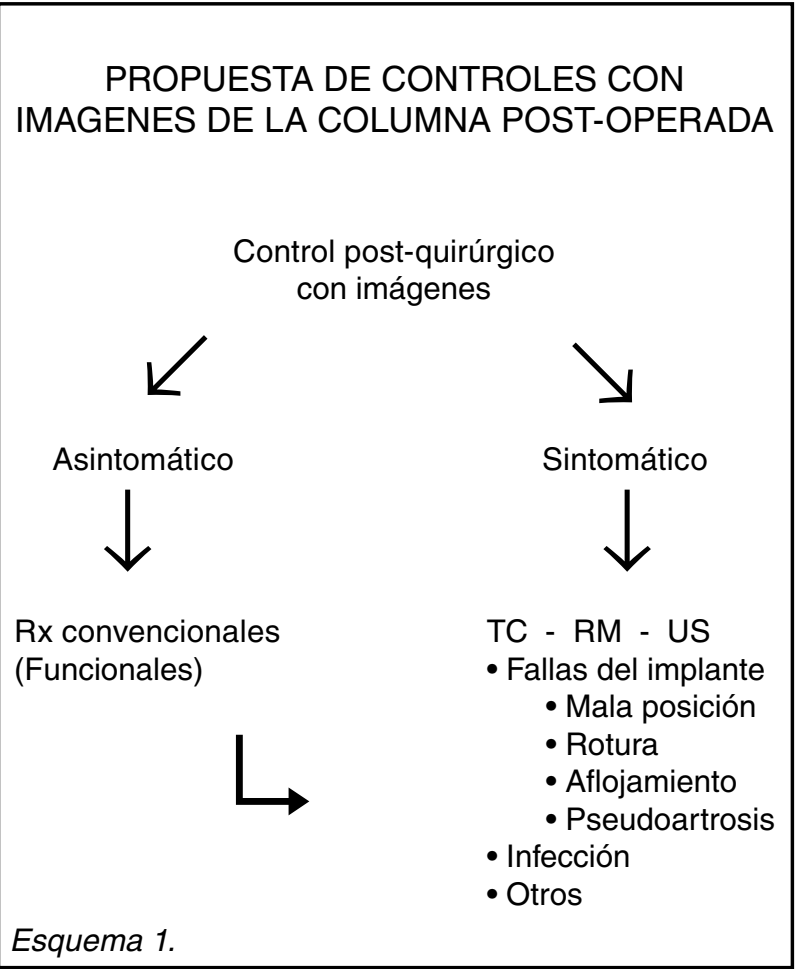




\section{PARAMETROS A EVALUAR EN LOS CONTROLES POSTOPERATORIOS CON IMAGENES}

$\begin{aligned} & \text { Controles } \\ & \text { post-quirúrgicos }\end{aligned}$
$\begin{aligned} & \text { Estado de la fusión } \\ & \text { Pseudoartrosis } \\ & \text { Cambios degenerativos } \\ & \text { Esquema 2. }\end{aligned}$
Infección

\section{Comentarios finales}

Los avances en el tratamiento de las enfermedades de la columna vertebral, modificaron las indicaciones quirúrgicas de la artrodesis, siendo su principal indicación las complicaciones dolorosas de la enfermedad degenerativa, sin respuesta al tratamiento médico. Del mismo modo, se están usando las artroplastías cervicales en el tratamiento de la enfermedad degenerativa complicada, con buenos resultados a corto plazo, aún en espera de estudios de validación y definiciones más precisas de sus indicaciones.

Hay controversia en patología discal degenerativa en cuanto al valor de estas innovaciones en el resultado de los pacientes operados. Recientes revisiones críticas de la literatura concluyen que los estudios publicados sobre tratamiento quirúrgico de las complicaciones de la enfermedad degenerativa no son de buena calidad, con pocas diferencias en el seguimiento de los tratados con cirugía o con tratamiento médico. Son necesarios estudios randomizados de largo plazo para precisar sus indicaciones quirúrgicas y confirmar las aparentes ventajas de todos estos avances ${ }^{(27,54)}$.

Las complicaciones de la cirugía vertebral pueden ser difíciles de diagnosticar y manejar. El seguimiento post-operatorio estándar se hace con radiografía simple, que con gran frecuencia da información muy útil; sin embargo, la caracterización de las complicaciones necesita de modalidades seccionales.

Finalmente, el conocimiento de todos estos factores por sí solos no es de beneficio real para el tratante y su paciente: únicamente la estrecha colaboración entre clínicos y radiólogos influirá en un resultado exitoso, a través de la detección precoz de las posibles complicaciones.

\section{Agradecimientos}

Mis agracedimientoa a la Dra. Sara Muñoz y al Dr. Roberto Postigo por sus invaluables aportes críticos al presente trabajo.

\section{Bibliografía}

1. Rojas D. Enfermedades de la Columna Vertebral: Pasado, Presente y Futuro de su Manejo Quirúrgico. Rev. Chil Neuro-Psiquiat 2001; 39: 35-40.

2. Dubousset J. Spinal Instrumentation, Source of Progress, but also Revealing Pitfalls. Bull Acad Natl Med 2003; 187: 523-533.

3. Rojas R, Hamide J, D’Antonio M, Castillo M. Imaging the Postoperative Cervical Spine. Appl Radiol 2002; 31: 27-131.

4. Mohan A, Kaushik D, History of Surgery for the Correction of Spinal Deformity. Neurosurg Focus. http// www.medscape.com/viewarticle/448306. Acceso 10/04/2008.

5. Slone RM, mcenery K, Bridwell KH, Montgomery WJ. Principles and Imaging of Spinal Instrumentation. Radiol Clin North Am 1995; 33: 189-211.

6. Foster MR. A Functional Classification of Spinal Instrumentation. Spine J 2005; 5: 682-694.

7. Platzer P, Thalhammer G, Sarahrudi K, Kovar K, Kovar F, Vekszler G, Vécsei V, Gaebler C. Nonoperative Management of Odontoid Fractures Using a Halo thoracic Vest. Neurosurgery 2007; 6: 522-529.

8. Lee SC, Chen JF, Lee ST. Complications of Fixation to the Occiput-Anatomical and Design Implications. Br J Neurosurg 2004; 18: 590-597.

9. Goel A. Editorial. Craniovertebral anomalies: Rol for Craniovertebral alignment. Neurology India 2004; 52 : 427-429.

10. Vaccaro AR, Lim MR, Lee JY. Indications for Surgery and Stabilization Techniques of the Occipito-cervical Junction. Injury 2005; 36 Suppl 2: B 44-53.

11. Matsunaga $S$, ljiri $K$, Koga $H$. Results of a Longer than 10-year follow-Up of Patients with Rheumatoid Arthritis Treated by Occipitocervical Fusions. Spine 2000; 25 : 1749-1753.

12. Dickman CA, Sonntag VK, Papadopulos SM, Hadley MN. The Inferior Spinous Method of Posterior Atlantoaxial Arthrodesis J Neurosurg 1991; 74: 190-198.

13. Agrillo U, Simonetti G, Hernández R, Di Benedetto A, lacovino F, Chiappetta F. Halifax Interlaminar Clamps for Posterior Atlanto-axial Arthrodesis with Spinal Fusion. J Neurosurg Sci 1994; 38: 105-110.

14. Rao G, Apfelbaum RI. Odontoid Screw Fixation for Fresh and Remote Fractures Nerology India 2005; 53: 416-423.

15. Gluf W, Schmidt M, Apfelbaum R. C1-C2 Transarticular Screw Fixation: a Review of 191 Adult's Patients with Regard to Surgical Indication, Fusion Rate, Complications and Lessons Learned. J Neurosurg Spine 2005; 2: 155-163.

16. Fountas KN, Kapsalaki EZ, Karampelas I, Feltes $\mathrm{CH}$, Dimopoulos VG Machinis TG, et al. Results of Longtern Follow-up in Patients Undergoing to Anterior Screw Fixation for Type II and Rostral Type II Odontoid Fractures. Spine 2005; 30: 661-669.

17. Rhee JM, Park JB, Yang JY, Riew D. Indications and Techniques for Anterior Cervical Plating. Neurology India 2005; 53: 433-439.

18. Gonugunta V, Krishnane AA, Benzel EC. Anterior Cervical Plating. Neurology India 2005; 53: 424-432.

19. Lowery GI, Mc Donaugh RF. The Significance of Hardware Failure in anterior Cervical Plate Fixation. 
Patient with 2 to 7 Years of Follow up. Spine 1998; 23: 181-196.

20. Hilibrand AS, Robbins M. Adjacent Segment Degeneration and Adjacent Segment Disease: the Consequences of Spinal Fusion. Spine J 2004 (4) (6 Suppl): 190-194.

21. Matgé G, Leclercq TA. Rationale for Interbody Fusion with Threaded Titanium Cages at Cervical and Lumbar Levels. Results on 357 Cases. Acta Neurochirg 2000; 142: 425-433.

22. Kulkarni AG, Hee HT, Wong HK. Solis Cage (PEEK) for Anterior Cervical Fusion: Preliminary Radiological Results with Emphasis on Fusion and Subsidence. Spine J 2007; 7: 205-209.

23. Mastronardi L, Ducati A, Ferrante L. Anterior Cervical Fusion with Polyetheretherketone (PEEK) Cages in the Treatment of Degenerative Disk Disease. Preliminary Observation in 36 Consecutive Cases with a Minimum 12 Month Follow-up. Acta Neurochirg 2006; 148: 307312.

24. Hanley SD, Gun MT, Osti O, Sanan EM. Radiology of Intervertebral Cages in Spinal Surgery. Clin Radiol 1999; 54: 201-206.

25. Van Jonbergen HP, Spruit M, Anderson PG, Pavlov PW. Anterior Cervical Interbody Fusion with a Titanium Box Cage: Early Radiological Assessment of Fusion and Subsidence. Spine J 2005; 5: 645-649.

26. Auguste KI, Chin C, Acosta FL, Ames CP. Expandable Cylindrical Cages in Cervical Spine: a Review of 22 Cases. J Neurosurg Spine. 2006; 4: 285-291.

27. González-Darder JM, Pesuto-Martínez JV, Feliu-Tatay R. Evolución de la Artrodesis Cervical Post-discectomía: Injerto Óseo, Caja Íntersomática y Placa-Caja. Neurocirugía. 2006; 2: 140-147.

28. Sasso RC, Le Huec JC, Shaffrey C. Spine Interbody Research Group. Iliac Crest Bone Graft Donor Site Pain after Anterior Lumbar Interbody Fusion: A Prospective Patient Satisfaction Outcome Assessment. J Spinal Disord J Tech 2005; 18: (S) 77-81.

29. Malloy Km, Hillibrand AS, Autograft versus Allograft in Degenerative Cervical Spine Disease. Clin Orthop Relat Res 2002; 394: 27-38.

30. Samartzis D, Shen FH, Matthews DK, Yoon ST, Goldberg EJ, An HS. Comparison of Allograft to Autograft in Multilevel Anterior Cervical Discectomy and Fusion with Rigid Plate Fixation. Spine J 2003; 3: 451-459.

31. Habal MB. Different Forms of Bone Grafts. In: Habal MB, Reddi AH, eds. Bone Grafts and Bone Substitutes. Philadelphia, Pa: Saunders, 1992; 6-8.

32. Beaman FD, Bancroft LW, Peterson J J, Kransdorf M J, Menke DM, De Orio JK. Imaging Characteristics of Bone Graft Materials. Radiographics 2006; 26:373-388.

33. De Long, Jr. WG, Einkorn TA, Koval K, Mc Kee M, Smith W, Sanders R, et al. Bone Graft and Bone Graft Substitutes in Orthopaedic Trauma Surgery. A Critical Analysis. J Bone Joint Surg Am 2007; 89: 649-665.

34. Arnold PM, Bryniarski M, Mc Mahon JK. Posterior Stabilization of Subaxial Cervical Spine Trauma: Indications and Techniques. Injury 2005; 36:(S) 36-43.

35. Espinoza-Larios A, Ames CP, Chamberlain MS, Sonntag VKH, Dickman CA, Crawford NR. Biomechanical Comparison of Two-level Cervical Locking Posterior Screw/
Rod Techniques The Spine J 2007; 7: 194-204.

36. Coric D, Finger F, Boltes P. Prospective Randomized Controlled Study of Bryan Cervical Disc: Early Clinical Results from a Single Investigational Site. Neurosurg Spine 2006; 4: 31-35.

37. Pimenta L, Mcafee PC, Capuccino A, Cunningham BW, Díaz R, Coutinho E. Superiority of Multilevel Cervical Arthroplasty Outcomes versus Single-level Outcomes: 229 Consecutive PCM prostheses. Spine 2007; 32: 1.337-1.334.

38. Mummaneni PV, Burkus JK, Haid RW, Traynelis VC, Zdeblick TA. Clinical and Radiographic Analysis of Cervical Disk Arthroplasty Compared with Allograft Fusion: a Randomized Controlled Clinical Trial. Neurosurg Spine 2007; 6: 198-209.

39. Leung C, Casey AT, Goffin J, Kehr P, Liebig K, Lind B, et al. Clinical Significance of Heterotopic Ossification in Cervical Disc Replacement: a Prospective Multicenter Clinical Trial. Neurosurgery 2005; 57: 759-763.

40. Mehren C, Suchomel P, Grochulla F, Barsa P, Sourkova $P$, el al. Heterotopic Ossification in Total Cervical Disc Replacement. Spine 2006; 31: 2.802-2.806.

41. Cummins BH, Robertson JT; Gill SS. Surgical Experience with an Implant Artificial Cervical Joint J Neurosurg 1998; 88: 943-948.

42. Sekhon LHS, Ball JR. Artificial Cervical Disk Replacement Principles, Types and Technique. Neurology India 2005; 53: 445-450.

43. Mehren C, Mayer HM. Artificial Disk Replacement. An Update. Neurology India 2005; 63: 440-444.

44. Porchet F, Metcalf NH. Clinical outcomes with the Prestige II cervical disc: preliminary results from a prospective randomized clinical trial http://www.medscape.com/ viewarticle/489863. Acceso 21/03/2008.

45. Anderson PA, Rouleau JP. Intervertebral Disc Arthroplasty. Spine 2004 ; 29: 2786- 2799.

46. Willert HG, Buckhorn GH, Hess T. The Significance of Wear and Material Fatigue in Loosening of Hip Prosthesis. Orthopade 1989; 18: (S) 350-369.

47. Anderson PA, Sasso RC, Rouleau JP, Carlson CS, Goffin J. Cervical Disk: Wear Properties and Early Clinical Results. Spine J 2004; 4: (S) 303-309.

48. Kulkarni AG, Diwan AD. Prosthetic Lumbar disc replacement for degenerative disc disease. Neurology India 2005; 53: 499-505.

49. Mc Afee PC. The Indications for Lumbar and Cervical Disk Replacement. Spine J 2004; 4: (S)177-181.

50. Ray CD. Threaded Fusion Cages for Lumbar Interbody Fusions: an Economic Comparison with 360 Degrees Fusions. Spine 1997; 22: 681-685.

51. Park JB, Cho YS, Riew K. Development of Adjacentlevel ossification in Pati- ents with an Anterior Cervical Plate. J Bone Joint Surg Am 2005; 87: 558-563.

52. Young PM, MD, Berquist TH, Bancroft LW, Peterson J.J. Complications of Spinal Instrumentation. Radiographics 2007; 27: 775-789.

53. Douglas-Akinwande AC, Buckwalter KA, Rydberg J, Rankin JL, Choplin R.H. Multichannel CT: Evaluating the Spine in Postoperative Patients with Orthopedic Hardware. Radiographics 2006; 26: (S) 97-110.

54. Deyo RA, Nachemson A, Mirza SK. Spinal Fusion Surgery- The Case for Restraint N Engl J Med 2004; 350: $722-726$. 